\title{
Research on Sustainable Development Ability and Spatial-Temporal Differentiation of Urban Human Settlements in China and Japan Based on SDGs, Taking Dalian and Kobe as Examples
}

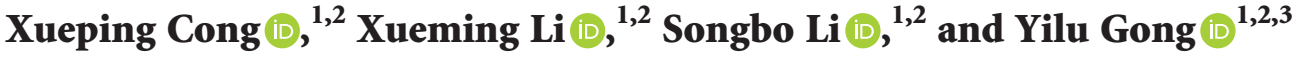 \\ ${ }^{1}$ School of Geography, Liaoning Normal University, Dalian 116029, China \\ ${ }^{2}$ Human Settlements Research Center, Liaoning Normal University, Dalian 116029, China \\ ${ }^{3}$ Art and Design School, Dalian Polytechnic University, Dalian 116034, China
}

Correspondence should be addressed to Xueping Cong; congxueping@163.com

Received 16 August 2020; Revised 18 October 2020; Accepted 28 December 2020; Published 20 January 2021

Academic Editor: Jianhong (Cecilia) Xia

Copyright ( $\odot 2021$ Xueping Cong et al. This is an open access article distributed under the Creative Commons Attribution License, which permits unrestricted use, distribution, and reproduction in any medium, provided the original work is properly cited.

\begin{abstract}
The sustainable development of the human settlements (HS) has become a global universal program. The comparison of cities in different countries is of great significance to provide international experience for future urban construction. Combined with the UN 2030 Sustainable Development Goals (SDGs), this paper establishes an evaluation index system for the sustainable development ability of urban HS and constructs a three-dimensional research framework of "development-coordination-sustainability," which compares the sustainable development ability of the HS of Dalian, China, and Kobe, Japan, from 2005 to 2018 and explores the spatial evolution characteristics and obstacle factors of the HS of the two cities. The results show that (1) the development degree of the HS of the two cities is on the rise. The development level of Kobe is always higher than that of Dalian, and the gap is gradually narrowing; Kobe has advantages in natural and residential environment, while Dalian has advantages in cultural and economic environment. (2) The coordination degree of the development of the HS of the two cities has improved steadily, and the coordination degree of Kobe is better than that of Dalian. (3) The sustainability of the development of the HS of the two cities is fluctuating, and the average sustainable growth rate of Dalian is higher than that of Kobe. (4) The sustainable development space of the HS in Dalian presents a pattern of "high in the south and low in the north," and the spatial characteristics of the subsystems are different; the main obstacles have changed from economic-natural to economic-natural-cultural-public services, and the obstacles to development in districts are different. (5) The sustainable development space of the HS in Kobe has a high level of development in the southeast, radiating to the surrounding area, and the spatial characteristics of the subsystems are different; the main obstacles have changed from economic-cultural-natural to economic-natural-population, and the obstacles to development in districts are different. Finally, it puts forward targeted suggestions for the sustainable construction of Dalian. This paper can provide methodological reference for quantitative assessment of the sustainable development of HS and provide policy reference for scientific planning of the construction of HS.
\end{abstract}

\section{Introduction}

As a complex, open, and dynamic giant system, the urban HS is an organic combination of material and nonmaterial environments needed by residents. Compared with the traditional HS, the sustainable HS emphasizes the simultaneous improvement of the growth rate and quality. It also underlines the continuity, coordination, and stability of development including economy, ecological environment, spiritual culture, living conditions, and other factors. With the acceleration of globalization, urbanization, and informatization, the urban population has increased from 746 million in 1950 (29.6\% of the global population) to more than half of the population living in cities in 2008 [1]. While capital, material, information, and population continue to gather in cities, it has also brought about a series of 
unsustainable development problems, such as excessive consumption of resources, deterioration of the ecological environment, and disorderly expansion of urban space, etc. which affects the healthy development of human-land relationship and the improvement of the quality of HS. Especially the sudden arrival of the COVID-19 epidemic threatens urban development. It has caused economic losses, social turbulence, poverty issues, the destruction of health systems, education issues, etc. on a global scale and has brought new and severe challenges to the sustainable development of the HS.

The science of HS originated from the theory of ekistics first proposed by the Greek architect C. A. Doxiadis in the 1950s. Subsequently, the United Nations first held UN Conference on HS (Habitat I) in Vancouver in 1976 and established the United Nations Commission on HS in 1978; this conference has promoted the world's attention to HS. The HS has the characteristics of interdisciplinary integration, which makes the data of the HS research diverse, wide-scale, rich in perspective, and deepened in content. The data come from interviews based on the subjective feelings of residents [2], questionnaires [3], and official statistical data [4]. With the rapid development of science and technology, data acquisition methods are more advanced, such as night light data [5], vegetation coverage data [6], land cover data [7], and other remote sensing image data, as well as electronic map points of interest [8], cell phone signaling data [9], social network data [10], real estate network data [11], and other network data, which enrich the new data environment composed of big data and open data. In terms of research methods, with the diversification of research data, research technical means are gradually enriched, mainly including quantitative analysis, such as entropy method [12], analytic hierarchy process [13], Delphi method [14], principal component analysis [15], structural equation model [16], and the combination of GIS spatial analysis and geographic measurement model, which is currently widely used $[17,18]$. On the scale of geospatial research, the administrative geographic scale includes global [19], country [20], urban agglomerations [21], cities [22], communities [23], urban fringe areas [24], and rural areas [3] and specific research areas include islands [25], basins [6], mountains [26], and informal settlements [27]. In terms of research perspective and research content, the content of human settlements is researched from macro to micro from multidisciplinary and multiperspective of environmental science [28], biology [29], history [30], sociology [31], geography [32], planning [33], and architecture [34], such as theoretical research on the HS, including the related concepts, development history, and disciplinary framework of the HS [35]; research on the spatial-temporal differentiation of environmental quality [36], livability [37], satisfaction [38], sustainability [39]; research on the coupling and coordination degree of $\mathrm{HS}$ system [40]; influencing factors of HS, including vegetation [41], resource richness [42], topography [43], new pollutants [44], social welfare [45], economy [46], and urban governance [47]. At the same time, the evolution of
HS also has varying degrees of impact on nature reserves [48], land use [49], cultural landscapes [34], and diseases [50].

In summary, the theory and practice of the HS have already produced fruitful research results, but the studies on the sustainability of the urban HS are mostly theoretical discussions, and quantitative indicators are rarely used for research, especially the direct comparative study between different countries based on first-hand data. In this paper, first of all, it selects the coastal cities of Kobe, Japan, and Dalian, China, in terms of the research objects. They have a high degree of similarity in terms of geographic environment, production, and lifestyle, and urban functions. However, due to differences in economic systems, resource utilization, government policies, etc., the development of urban HS is different. Second, in terms of indicator selection, compared with the selection of traditional urban HS quality indicators, this paper combines the United Nations 2030 Sustainable Development Goals and strives to build comprehensive and targeted indicators for the sustainable development of HS to make up for the lack of indicators for quantitative analysis of sustainability. Third, in terms of analysis methods, the combination of subjective and objective methods is used to determine the index weight in order to make the results more accurate, which not only reduces the subjective bias, but also avoids the problem of index value selection. Then, it compares and analyses the evolution characteristics and differences of the sustainable development capacity of HS in Dalian and Kobe in the past 14 years. This paper attempts to construct a measurement model for the sustainable development of HS to quantitatively describe the practical significance of basic parameters such as the degree of development, coordination, and sustainability, which can better interpret the sustainable development of HS under long-term conditions. The method of GIS spatial analysis is used to explore the temporal and spatial differentiation pattern and obstacle factors of the sustainable development of the HS in each city, in order to further understand the advantages and disadvantages of the development of each city and to provide advice and suggestions for the construction and management of the HS in Dalian. Not only has it enriched the research on the HS and made up for the lack of empirical cases, it also proposed a new assessment framework for the sustainable development of the HS, which helps to summarize the inherent laws of the sustainable development of the HS. It can also provide reference for the sustainable and coordinated development of coastal cities with similar development backgrounds.

\section{Overview of the Study Area}

Both Kobe in Japan and Dalian in China have been rated as livable cities and have many similarities. (1) Historical and cultural background: both Kobe and Dalian have been invaded by foreign forces in modern history, and they have integrated multinational cultural backgrounds. Kobe was jointly managed by European and American powers. Dalian was once reduced to a Russian lease and was invaded by Japan for 40 years. (2) Natural conditions: Kobe and Dalian 
are both surrounded by mountains and seas. Kobe is located at $34^{\circ} 41^{\prime}$ north latitude and $135^{\circ} 1^{\prime}$ east longitude. It is located in the southeastern part of Hyogo Prefecture in the Kinki region of western Japan, along the coast of the Seto Inland Sea, facing Osaka Bay, and the Rokko Mountain System traverses the northern part of the city from east to west. Dalian is located at $38^{\circ} 43^{\prime}-40^{\circ} 12^{\prime}$ north latitude and $120^{\circ} 58^{\prime}-123^{\circ} 31^{\prime}$ east longitude. It is located on the southernmost coast of Liaoning Province, China, with the Yellow Sea to the east, the Bohai Sea to the west, and the Shandong Peninsula to the south. In terms of climate, the two cities have a pleasant climate, four distinct seasons, no scorching heat in summer, no severe cold in winter, abundant sunshine, and concentrated rainfall. (3) Urban functions: Kobe and Dalian are both trading port cities and transportation hub cities. Kobe is a city designated by Japanese government decree, the function of the city is mainly foreign trade, industrial economy, tourism, etc. Dalian is a city separately listed in China's planning; it mainly takes equipment manufacturing, petrochemical, electronic information, and high-tech as its pillar industries. At the same time, it is a famous tourist city.

The research scope of Kobe is the 9 districts under its administrative division, namely, Higashinada-ku, Nada-ku, Chuo-ku, Hyogo-ku, Nagata-ku, Suma-ku, Tarumi-ku, Kita$\mathrm{ku}$, and Nishi-ku. The scope of administrative divisions of Chinese and Japanese cities is different. In order to make the results comparable, the two cities need to be on the same research scale. Therefore, 6 districts within the scope of Dalian are selected as the research area, including Zhongshan District, Xigang District, Shahekou District, Ganjingzi District, Lushunkou District, and Jinzhou District.

\section{Index System Construction and Methods}

3.1. Construction of an Evaluation Index System Based on SDGs for the Sustainable Development Ability of Urban Human Settlements. The United Nations Sustainable Development Goals (SDGs) are 17 global development goals officially adopted on September 25, 2015, after the completion of the United Nations Millennium Development Goals (MDGs). They are designed to promote economic prosperity in an integrated manner while protecting the Earth from 2015 to 2030, which not only achieve economic growth, but also address social needs, promote the protection of natural resources and the ecological environment, and strive to create a sustainable, inclusive, and resilient future settlement. Among them, Goal 11 "Sustainable Cities and Communities" focuses on issues such as housing, basic services, transportation facilities, living environment, public space, and other issues in the HS. In order to evaluate the sustainable development ability of the urban HS more objectively, not only the quality of the residential area, but also the natural conditions, population quality, and economic development and other aspects must also be considered. Therefore, while comprehensively considering the other 16 sustainable development goals in addition to "Goal 11," the International Green Model City (IGMC) Standards 3.0 proposed by the Global Forum on
Human Settlements and existing research should also be referred [51, 52]. Following the principles of people-oriented, uniformity of data statistics, comprehensiveness, comparability, and operability of indicators, 48 indicators are selected from the four aspects of natural environment, humanity environment, HS, and economic environment to build the evaluation index system of sustainable development ability of HS (Table 1).

3.2. Data Sources. The spatial vector data of Dalian comes from Dalian Master Plan (2009-2020); the spatial vector data of Kobe comes from the website of the Japanese Government Statistics Comprehensive Window and the Kobe Master Plan; the economic and social data of Dalian comes from 2005-2019 Dalian Statistical Yearbook, Liaoning Province Statistical Yearbook, and regional national economic and social development statistical bulletins; the socio-economic data of Kobe comes from the 2005-2019 Kobe Statistical Yearbook, the statistical information of various industries, and the annual tax statistics bulletins; the relief degree of land surface of Dalian is calculated from SRTM DEM $90 \mathrm{~m}$ data; the housing price data of Dalian are taken from Anjuke; the exchange rate is calculated according to the average exchange rate value of the People's Bank of China for the year. This paper uses the range standardization method to process the data, and some of the data are the result of statistical data calculation.

Among them, the temperature-humidity index is one of the main evaluation indicators of human comfort. It was used earlier by the National Weather Service [53], and then widely used worldwide. It reflects the heat exchange between the human body and the surrounding environment through temperature and humidity. The calculation equation is

$$
\mathrm{THI}=(1.8 t+32)-0.55 \times(1-f)(1.8 t-26) .
$$

In the equation, THI is the temperature and humidity index, $t$ is the temperature in degrees celsius $\left({ }^{\circ} \mathrm{C}\right)$, and $f$ is the relative humidity (\%).

The wind effect index, proposed by American biologist Terjung [54], represents the influence of wind speed, temperature, and solar radiation on the comfort of human skin under different environments; that is, the amount of heat exchange per unit area of the body surface. The calculation equation is

$$
\mathrm{WEI}=-(10 \sqrt{v}+10.45-v) \times(33-t)+\frac{200 S}{D} .
$$

In the equation, WEI is the wind efficiency index, $v$ is the average wind speed $(\mathrm{m} / \mathrm{s}), t$ is the temperature in degrees Celsius $\left({ }^{\circ} \mathrm{C}\right), S$ is the sunshine hours (h), and $D$ is the day length (h).

The clothing index, proposed by the Australian scholar Freitas [55], reflects the uncomfortable effects of people wearing different clothes to adjust the climate environment. Its calculation equation is

$$
\mathrm{ICL}=\frac{33-t}{0.155 H}-\frac{H+a R \cos \alpha}{(0.62+19 \sqrt{v}) H} .
$$


TABLE 1: The evaluation index system and weight of urban human settlements sustainable development ability based on SDGs.

\begin{tabular}{|c|c|c|c|c|c|c|}
\hline System layer & Index layer & Unit & $\begin{array}{l}\text { Corresponding to the } \\
\text { target in SDGs }\end{array}$ & $\begin{array}{l}\text { Entropy } \\
\text { weight }\end{array}$ & $\begin{array}{l}\text { Analytic } \\
\text { hierarchy } \\
\text { process } \\
\text { weight }\end{array}$ & $\begin{array}{l}\text { Comprehensive } \\
\text { weight }\end{array}$ \\
\hline \multirow{12}{*}{$\begin{array}{l}\text { Natural } \\
\text { environment } \\
\left(A_{1}\right)\end{array}$} & $\begin{array}{l}\text { Relief degree of land surface } \\
\qquad\left(B_{1}\right)\end{array}$ & $\mathrm{m}$ & Goal 15: life on land & 0.0162 & 0.0207 & 0.0225 \\
\hline & $\begin{array}{c}\text { Temperature-humidity } \\
\text { index }\left(B_{2}\right)\end{array}$ & ${ }^{\circ} \mathrm{C}$ & $\begin{array}{l}\text { Goal 13: climate } \\
\text { action }\end{array}$ & 0.0189 & 0.0403 & 0.0337 \\
\hline & Wind effect index $\left(B_{3}\right)$ & $\mathrm{kcal} / \mathrm{m}^{2} \cdot \mathrm{h}$ & $\begin{array}{l}\text { Goal 13: climate } \\
\text { action }\end{array}$ & 0.0182 & 0.0390 & 0.0326 \\
\hline & Clothing index $\left(B_{4}\right)$ & clo & $\begin{array}{l}\text { Goal 13: climate } \\
\text { action }\end{array}$ & 0.0206 & 0.0509 & 0.0396 \\
\hline & $\begin{array}{c}\text { Standardized precipitation } \\
\text { index }\left(B_{5}\right)\end{array}$ & - & $\begin{array}{l}\text { Goal 13: climate } \\
\text { action }\end{array}$ & 0.0073 & 0.0427 & 0.0216 \\
\hline & Air quality index $\left(B_{6}\right)$ & - & $\begin{array}{l}\text { Goal 11: sustainable } \\
\text { cities and } \\
\text { communities }\end{array}$ & 0.0157 & 0.0971 & 0.0477 \\
\hline & $\begin{array}{l}\text { Green coverage rate of } \\
\text { built-up area }\left(B_{7}\right)\end{array}$ & & Goal 15: life on land & 0.0306 & 0.0167 & 0.0277 \\
\hline & Park area per capita $\left(B_{8}\right)$ & $\mathrm{m}^{2}$ & $\begin{array}{l}\text { Goal 11: sustainable } \\
\text { cities and } \\
\text { communities }\end{array}$ & 0.0149 & 0.0191 & 0.0207 \\
\hline & Sewage treatment rate $\left(B_{9}\right)$ & $\%$ & $\begin{array}{l}\text { Goal 6: clean water } \\
\text { and sanitation }\end{array}$ & 0.0621 & 0.0239 & 0.0472 \\
\hline & $\begin{array}{l}\text { Harmless treatment rate of } \\
\text { domestic garbage }\left(B_{10}\right)\end{array}$ & $\%$ & $\begin{array}{l}\text { Goal 11: sustainable } \\
\text { cities and } \\
\text { communities }\end{array}$ & 0.0082 & 0.0202 & 0.0158 \\
\hline & $\begin{array}{l}\text { Energy consumption per } \\
\text { unit of GDP }\left(B_{11}\right)\end{array}$ & tce/million dollars & $\begin{array}{c}\text { Goal 12: responsible } \\
\text { consumption and } \\
\text { production }\end{array}$ & 0.0094 & 0.0294 & 0.0203 \\
\hline & $\begin{array}{l}\text { Water resources per capita } \\
\qquad\left(B_{12}\right)\end{array}$ & $\mathrm{m}^{3}$ & $\begin{array}{l}\text { Goal 6: clean water } \\
\text { and sanitation }\end{array}$ & 0.0225 & 0.0587 & 0.0444 \\
\hline \multirow{11}{*}{$\begin{array}{l}\text { Humanity } \\
\text { environment } \\
\left(A_{2}\right)\end{array}$} & Population density $\left(B_{13}\right)$ & person $/ \mathrm{km}^{2}$ & $\begin{array}{l}\text { Goal 11: sustainable } \\
\text { cities and } \\
\text { communities }\end{array}$ & 0.0068 & 0.0491 & 0.0223 \\
\hline & $\begin{array}{l}\text { Natural population growth } \\
\text { rate }\left(B_{14}\right)\end{array}$ & $\%$ & $\begin{array}{l}\text { Goal 11: sustainable } \\
\text { cities and } \\
\text { communities }\end{array}$ & 0.0042 & 0.0457 & 0.0169 \\
\hline & Gender ratio $\left(B_{15}\right)$ & $\%$ & $\begin{array}{l}\text { Goal 5: gender } \\
\text { equality }\end{array}$ & 0.0141 & 0.0252 & 0.0231 \\
\hline & Aging rate $\left(B_{16}\right)$ & $\%$ & $\begin{array}{l}\text { Goal 11: sustainable } \\
\text { cities and } \\
\text { communities }\end{array}$ & 0.0123 & 0.0408 & 0.0274 \\
\hline & $\begin{array}{c}\text { Minimum living security } \\
\text { rate }\left(B_{17}\right)\end{array}$ & $\%$ & Goal 1: no poverty & 0.0071 & 0.0275 & 0.0171 \\
\hline & $\begin{array}{l}\text { Public collection of books } \\
\text { per } 10,000 \text { population }\left(B_{18}\right)\end{array}$ & volume & $\begin{array}{l}\text { Goal 11: sustainable } \\
\text { cities and } \\
\text { communities }\end{array}$ & 0.0110 & 0.0040 & 0.0081 \\
\hline & $\begin{array}{l}\text { Teacher-student ratio in } \\
\text { primary and secondary } \\
\text { schools }\left(B_{19}\right)\end{array}$ & $\%$ & $\begin{array}{l}\text { Goal 4: quality } \\
\text { education }\end{array}$ & 0.0225 & 0.0129 & 0.0208 \\
\hline & $\begin{array}{l}\text { Number of college students } \\
\text { per } 10,000\left(B_{20}\right)\end{array}$ & person & $\begin{array}{l}\text { Goal 4: quality } \\
\text { education }\end{array}$ & 0.0123 & 0.0071 & 0.0115 \\
\hline & $\begin{array}{l}\text { Per capita education } \\
\text { expenditure }\left(B_{21}\right)\end{array}$ & dollar & $\begin{array}{l}\text { Goal 4: quality } \\
\text { education }\end{array}$ & 0.0301 & 0.0066 & 0.0172 \\
\hline & $\begin{array}{c}\text { Number of cultural centers } \\
\text { owned by } 10,000 \text { people } \\
\qquad\left(B_{22}\right)\end{array}$ & number & $\begin{array}{l}\text { Goal 11: sustainable } \\
\text { cities and } \\
\text { communities }\end{array}$ & 0.0385 & 0.0034 & 0.0140 \\
\hline & $\begin{array}{l}\text { The proportion of science } \\
\text { and technology expenditure } \\
\text { in fiscal expenditure }\left(B_{23}\right)\end{array}$ & $\%$ & $\begin{array}{l}\text { Goal 9: industry, } \\
\text { innovation and } \\
\text { infrastructure }\end{array}$ & 0.0412 & 0.0037 & 0.0151 \\
\hline
\end{tabular}


TABle 1: Continued.

\begin{tabular}{|c|c|c|c|c|c|c|}
\hline System layer & Index layer & Unit & $\begin{array}{l}\text { Corresponding to the } \\
\text { target in SDGs }\end{array}$ & $\begin{array}{l}\text { Entropy } \\
\text { weight }\end{array}$ & $\begin{array}{l}\text { Analytic } \\
\text { hierarchy } \\
\text { process } \\
\text { weight }\end{array}$ & $\begin{array}{l}\text { Comprehensive } \\
\text { weight }\end{array}$ \\
\hline \multirow{14}{*}{$\begin{array}{l}\text { Living } \\
\text { environment } \\
\left(A_{3}\right)\end{array}$} & $\begin{array}{l}\text { Housing area per capita } \\
\qquad\left(B_{24}\right)\end{array}$ & $\mathrm{m}^{2}$ & $\begin{array}{l}\text { Goal 11: sustainable } \\
\text { cities and } \\
\text { communities }\end{array}$ & 0.0118 & 0.0117 & 0.0144 \\
\hline & $\begin{array}{l}\text { Housing price-to-income } \\
\text { ratio }\left(B_{25}\right)\end{array}$ & $\%$ & $\begin{array}{c}\text { Goal 11: sustainable } \\
\text { cities and } \\
\text { communities }\end{array}$ & 0.0111 & 0.0117 & 0.0140 \\
\hline & Gas penetration rate $\left(B_{26}\right)$ & $\%$ & $\begin{array}{l}\text { Goal 7: affordable and } \\
\text { clean energy }\end{array}$ & 0.0217 & 0.0117 & 0.0195 \\
\hline & $\begin{array}{l}\text { Water supply penetration } \\
\text { rate }\left(B_{27}\right)\end{array}$ & $\%$ & $\begin{array}{l}\text { Goal 6: clean water } \\
\text { and sanitation }\end{array}$ & 0.0193 & 0.0233 & 0.0259 \\
\hline & $\begin{array}{c}\text { Mobile phone penetration } \\
\text { rate }\left(B_{28}\right)\end{array}$ & $\%$ & $\begin{array}{l}\text { Goal 9: industry, } \\
\text { innovation and } \\
\text { infrastructure }\end{array}$ & 0.0102 & 0.0050 & 0.0087 \\
\hline & $\begin{array}{l}\text { Internet penetration rate } \\
\qquad\left(B_{29}\right)\end{array}$ & $\%$ & $\begin{array}{l}\text { Goal 9: industry, } \\
\text { innovation and } \\
\text { infrastructure }\end{array}$ & 0.0184 & 0.0070 & 0.0139 \\
\hline & Road network density $\left(B_{30}\right)$ & $\mathrm{km} / \mathrm{km}^{2}$ & $\begin{array}{l}\text { Goal 11: sustainable } \\
\text { cities and } \\
\text { communities }\end{array}$ & 0.0613 & 0.0058 & 0.0231 \\
\hline & Road area per capita $\left(B_{31}\right)$ & $\mathrm{m}^{2}$ & $\begin{array}{l}\text { Goal 11: sustainable } \\
\text { cities and } \\
\text { communities }\end{array}$ & 0.0063 & 0.0073 & 0.0083 \\
\hline & $\begin{array}{l}\text { Number of buses per } 10,000 \\
\text { people }\left(B_{32}\right)\end{array}$ & number & $\begin{array}{l}\text { Goal 11: sustainable } \\
\text { cities and } \\
\text { communities }\end{array}$ & 0.0095 & 0.0046 & 0.0081 \\
\hline & $\begin{array}{l}\text { Number of stadiums owned } \\
\text { by } 10,000 \text { people }\left(B_{33}\right)\end{array}$ & number & $\begin{array}{l}\text { Goal 11: sustainable } \\
\text { cities and } \\
\text { communities }\end{array}$ & 0.0672 & 0.0019 & 0.0138 \\
\hline & $\begin{array}{l}\text { Number of hospital beds } \\
\text { per } 10,000 \text { people }\left(B_{34}\right)\end{array}$ & number & $\begin{array}{l}\text { Goal 3: good health } \\
\text { and well-being }\end{array}$ & 0.0283 & 0.0067 & 0.0169 \\
\hline & $\begin{array}{c}\text { Number of physicians per } \\
10,000 \text { people }\left(B_{35}\right)\end{array}$ & person & $\begin{array}{l}\text { Goal 3: good health } \\
\text { and well-being }\end{array}$ & 0.0148 & 0.0081 & 0.0134 \\
\hline & $\begin{array}{l}\text { Number of welfare facilities } \\
\text { per } 100 \text { elderly people }\left(B_{36}\right)\end{array}$ & number & $\begin{array}{l}\text { Goal 11: sustainable } \\
\text { cities and } \\
\text { communities }\end{array}$ & 0.0267 & 0.0033 & 0.0115 \\
\hline & $\begin{array}{l}\text { Road accident mortality rate } \\
\qquad\left(B_{37}\right)\end{array}$ & $\%$ & $\begin{array}{c}\text { Goal 11: sustainable } \\
\text { cities and } \\
\text { communities }\end{array}$ & 0.0017 & 0.0354 & 0.0094 \\
\hline \multirow{11}{*}{$\begin{array}{l}\text { Economic } \\
\text { environment } \\
\left(A_{4}\right)\end{array}$} & GDP per capita $\left(B_{38}\right)$ & dollar & $\begin{array}{l}\text { Goal 8: decent work } \\
\text { and economic growth }\end{array}$ & 0.0250 & 0.0274 & 0.0320 \\
\hline & GDP growth rate $\left(B_{39}\right)$ & $\%$ & $\begin{array}{l}\text { Goal 8: decent work } \\
\text { and economic growth }\end{array}$ & 0.0167 & 0.0180 & 0.0212 \\
\hline & $\begin{array}{l}\text { Fiscal revenue growth rate } \\
\qquad\left(B_{40}\right)\end{array}$ & $\%$ & $\begin{array}{l}\text { Goal 8: decent work } \\
\text { and economic growth }\end{array}$ & 0.0142 & 0.0098 & 0.0144 \\
\hline & $\begin{array}{l}\text { The proportion of tertiary } \\
\text { industry in GDP }\left(B_{41}\right)\end{array}$ & $\%$ & $\begin{array}{l}\text { Goal 9: industry, } \\
\text { innovation and } \\
\text { infrastructure }\end{array}$ & 0.0182 & 0.0171 & 0.0216 \\
\hline & $\begin{array}{l}\text { Fixed asset investment } \\
\text { growth rate }\left(B_{42}\right)\end{array}$ & $\%$ & $\begin{array}{l}\text { Goal 8: decent work } \\
\text { and economic growth }\end{array}$ & 0.0052 & 0.0078 & 0.0078 \\
\hline & $\begin{array}{l}\text { Dependence on foreign } \\
\text { trade }\left(B_{43}\right)\end{array}$ & $\%$ & $\begin{array}{l}\text { Goal 17: partnership } \\
\text { for the goals }\end{array}$ & 0.0155 & 0.0057 & 0.0115 \\
\hline & Unemployment rate $\left(B_{44}\right)$ & $\%$ & $\begin{array}{l}\text { Goal 10: reduced } \\
\text { inequalities }\end{array}$ & 0.0060 & 0.0227 & 0.0143 \\
\hline & $\begin{array}{c}\text { Per capita disposable } \\
\text { income growth rate }\left(B_{45}\right)\end{array}$ & $\%$ & Goal 1: no poverty & 0.0138 & 0.0227 & 0.0217 \\
\hline & Engel coefficient $\left(B_{46}\right)$ & $\%$ & $\begin{array}{l}\text { Goal 8: decent work } \\
\text { and economic growth }\end{array}$ & 0.0631 & 0.0227 & 0.0463 \\
\hline & $\begin{array}{l}\text { Per capita food production } \\
\qquad\left(B_{47}\right)\end{array}$ & $\mathrm{kg}$ & Goal 2: zero hunger & 0.0648 & 0.0124 & 0.0347 \\
\hline & $\begin{array}{l}\text { Per capita production of } \\
\text { marine products }\left(B_{48}\right)\end{array}$ & $\mathrm{kg}$ & $\begin{array}{l}\text { Goal 14: life below } \\
\text { water }\end{array}$ & 0.0049 & 0.0053 & 0.0062 \\
\hline
\end{tabular}


In the equation, ICL is the clothing index; $t$ is the temperature in Celsius $\left({ }^{\circ} \mathrm{C}\right) ; \mathrm{H}$ is $75 \%$ metabolic rate of the human body $\left(\mathrm{W} / \mathrm{m}^{2}\right)$, this paper takes the metabolic rate under light activity, at this time $H=87 \mathrm{~W} / \mathrm{m}^{2} ; a$ is the human body's absorption of solar radiation, usually it takes 0.06 as the maximum value; $R$ is the solar radiation received by a unit area of land with vertical sunlight $\left(\mathrm{W} / \mathrm{m}^{2}\right)$, usually taken as the solar constant1367 $\left(\mathrm{W} / \mathrm{m}^{2}\right) ; \alpha$ is the solar altitude angle, taking the average value; and $v$ is the average wind speed $(\mathrm{m} / \mathrm{s})$.

The standardized precipitation index, is an indicator commonly used by the World Meteorological Organization to monitor the degree of drought. Reflecting the drought and flood situation in a certain period of time, it is obtained by calculating the precipitation in a long period of time through standardized transformation of normal distribution [56].

The air quality index is a dimensionless index that quantitatively describes the air pollution situation obtained by Mayer's improvement of the air quality index proposed by the US Environmental Protection Agency [57]. Its equation is

$$
\begin{aligned}
\mathrm{IAQI}_{i} & =\frac{\mathrm{IAQI}_{\mathrm{hi}}-\mathrm{IAQI}_{\mathrm{lo}}}{C_{\mathrm{hi}}-C_{\mathrm{lo}}} \times\left(C_{i}-C_{\mathrm{lo}}\right)+\mathrm{IAQI}_{\mathrm{lo}}, \\
\mathrm{AQI} & =\max \left\{\mathrm{IAQI}_{1}, \mathrm{IAQI}_{2}, \mathrm{IAQI}_{3}, \ldots, \mathrm{IAQI}_{n}\right\} .
\end{aligned}
$$

In the equation, $A Q I$ is the air quality index; $\mathrm{IAQI}_{i}$ is the air quality index of pollutant $i ; C_{i}$ is the concentration of pollutant $i ; C_{\mathrm{hi}}, C_{\mathrm{lo}}$ are, respectively, the high and low values of the similar pollutant concentration limit; IAQI $\mathrm{hi}_{\mathrm{hi}}, \mathrm{IAQI}_{\mathrm{lo}}$ are the corresponding air quality score Index of $C_{\mathrm{hi}}, C_{\mathrm{lo}} ; n$ is the pollutant item; the concentration standard of each pollutant refers to the Air Quality Guidelines for Particulate Matter, Ozone, Nitrogen Dioxide and Sulfur Dioxide issued by the World Health Organization.

\subsection{Research Method}

3.3.1. Combination Weighting Method. The entropy method is an objective weighting method, which has strong objectivity and high precision, but its application range is limited and the decision-maker's participation is poor. The analytic hierarchy process is a subjective weighting method. Experts judge the importance of various factors based on their experience. This method has a strong system, but it is too subjective and errors are prone to occur when there are too many indicators. In order to make the weighting results more accurate, this study uses a combination of subjective and objective methods to determine the indicator weights of the urban HS sustainable development ability evaluation system. Firstly, the entropy weight method and the analytic hierarchy process are used to calculate the weight, respectively, and then the combined weight is calculated by the principle of minimum information entropy.

Entropy method uses information entropy theory to evaluate the orderliness and utility of each indicator. The smaller the information entropy value of an indicator, the greater its information utility value and the weight of the indicator, indicating that the indicator is more important. On the contrary, the larger the information entropy, the smaller the information utility value, and the smaller the index weight, the smaller the importance for evaluation. Specific calculation steps:

(1) Standardize the raw data:

$$
\begin{gathered}
\text { Positive index } y_{i j}=\frac{x_{i j}-x_{i \min }}{x_{i \max }-x_{i \min }}, \\
\text { Negative index } y_{i j}=\frac{x_{i \max }-x_{i j}}{x_{i \max }-x_{i \min }} .
\end{gathered}
$$

In the equation, $y_{i j}$ is the $j$-th index of the $i$-th unit that has undergone dimensionless processing; $x_{i j}$ is the original value; $x_{i \min }, x_{i \max }$ are, respectively, the minimum and maximum value in the data of the $i$ unit.

(2) The proportion of the $j$-th index in the $i$-th unit:

$$
Y_{i j}=\frac{y_{i j}}{\sum_{i=1}^{n} y_{i j}} \text {. }
$$

(3) Information entropy value of the $j$-th index:

$$
e_{j}=-\frac{1}{\ln n} \sum_{i=1}^{n}\left(Y_{i j} \times \ln Y_{i j}\right), \quad e_{j} \in[0,1]
$$

(4) Coefficient of difference of the $j$-th index:

$$
d_{j}=1-e_{j}
$$

(5) The weight of the $j$-th index:

$$
w_{j}=\frac{d_{j}}{\sum_{j=1}^{m} d_{j}} .
$$

The analytic hierarchy process takes the multiobjective, multicriteria, and multielement decision-making problem as a system, uses the measurement theory to hierarchize the various factors, and calculates the order of each level through the fuzzy quantification method of qualitative indicators, providing a simple and optimized decision-making method for multi-index unstructured complex decision-making problems. The specific calculation steps are as follows:

(1) Establish a hierarchical structure model, which enables the relevant indicators of the research target to be decomposed into several levels according to different attributes from top to bottom. The indicators of the same level belong to the previous level and dominate the next level.

(2) Constructing judgment matrices at each level, in the process of inviting evaluators to judge the importance of pairs of indicators at the same level, and constructing a judgment matrix, the relative importance of important factors that have a greater impact on the research goal will be increased. The relative importance value of the secondary influencing factor will be reduced. 
(3) Hierarchical single sorting and consistency test, first calculate the maximum eigenvalue $\lambda_{\max }$ of the judgment matrix and its corresponding eigenvector $W$, and perform normalization with $W$, that is, the weight vector of each index; then perform consistency test, the calculation equation is

$$
\begin{aligned}
\mathrm{CI} & =\frac{\lambda_{\max }-n}{n-1}, \\
\mathrm{CR} & =\frac{\mathrm{CI}}{\mathrm{RI}} .
\end{aligned}
$$

In the equation, $\mathrm{CI}$ is the consistency index of the deviation of the judgment matrix, if $\mathrm{CI}=0$, the structure is consistent with the actual situation. The larger the value of $\mathrm{CI}$ is, the worse the consistency of the result obtained by the judgment matrix with the actual situation is; $n$ is the order of the matrix; CR is the consistency ratio, when $\mathrm{CR}<0.1$, the consistency of the judgment matrix is considered acceptable; RI is the random consistency index.

(4) Hierarchical total ranking and consistency test, calculate the weight of the relative importance of all factors of a certain level to the overall goal, which is the total ranking of the hierarchy.

This paper formulates corresponding questionnaires based on the constructed HS sustainability evaluation index system and invites 6 experts in the field of HS and sustainable development to compare the importance of the primary and secondary indicators and construct the corresponding judgment matrix. Taking the first-level index judgment matrix (Table 2) as an example, the eigenvector $W=[0.4588,0.2260,0.1436,0.1716]^{T}$ is obtained, the maximum eigenvalue is $\lambda_{\max }=4.0458, \mathrm{CR}=0.0172$, and the judgment matrix has satisfactory consistency after inspection, so the weight values of the system layer are 0.4588 , $0.2260,0.1436$, and 0.1716 . The same method can be used to obtain the weight of the index layer. It can be seen from Table 3 that all the second-level index judgment matrices can pass the consistency test and have relatively high credibility.

Determine the combined weight, in order to make the combined weight value as close as possible to the entropy weight method weight and the analytic hierarchy process weight, according to the principle of minimum relative information entropy, the combined weight is obtained by optimizing the Lagrangian multiplier method [58], the calculation equation is

$$
W_{j}=\frac{\left(w_{1 j} w_{2 j}\right)^{0.5}}{\sum_{j=1}^{n}\left(w_{1 j} w_{2 j}\right)^{0.5}}, \quad(j=1,2,3, \ldots, n) .
$$

In the equation, $W_{j}$ is the combined weight of the index $j$ and $w_{1 j}, w_{2 j}$ are, respectively, the entropy weight method and the analytic hierarchy process weight of the index $j$.

3.3.2. Measurement Model of Urban Human Settlements Sustainable Development Ability. The urban HS is an organic complex composed of natural system, humanity
TABLe 2: First-level index judgment matrix.

\begin{tabular}{lccccc}
\hline First-level index & $A_{1}$ & $A_{2}$ & $A_{3}$ & $A_{4}$ & $W_{i}$ \\
\hline$A_{1}$ & 1 & 2 & 3 & 3 & 0.4588 \\
$A_{2}$ & $1 / 2$ & 1 & 2 & 1 & 0.2260 \\
$A_{3}$ & $1 / 3$ & $1 / 2$ & 1 & 1 & 0.1436 \\
$A_{4}$ & $1 / 3$ & 1 & 1 & 1 & 0.1716 \\
\hline
\end{tabular}

system, residential system, and economic system. Each subsystem does not exist independently, but interacts and influences each other. On a certain spatial-temporal scale, long-term sustainable urban development and structural adjustment can make the HS not only meet the needs of contemporary reality, but also ensure the needs of future development. In order to evaluate the sustainable development ability of the harmonious and healthy urban HS, this research is based on the quality of the sustainable development of the HS, combined with the internal structure of the human settlements system and the external extension trend, starting from the three aspects of the development, coordination, and sustainability of the urban HS to conduct comprehensive research on the sustainable development ability. The equations are as follows:

Development degree of urban HS is a measure of the development level at a certain point in time. The higher the value, the better the development level. Its equation is

$$
\begin{aligned}
& h_{i}=\sum_{j=1}^{n}\left(w_{j} \times y_{i j}\right), \\
& H=\sum_{i=1}^{m}\left(W_{i} \times h_{i}\right) .
\end{aligned}
$$

In the equation, $h_{i}$ is the development level of the natural environment, the humanity environment, the living environment, and the economic environment; $w_{j}$ is the weight of each index; $y_{i j}$ is the standardized index value; $H$ is the development level of the urban HS; and $W_{i}$ is the system weight; when calculating the development level of the system layer separately, the index weight is the ratio of the original index weight to the weight of the system layer where it is located.

Coordination degree of urban HS, which measures the degree of coordination among the four systems of natural environment, humanity environment, residential environment and economic environment, characterizes the development balance of each system, and judges the mutual promotion or restriction of each system. The closer the value is to 1 , the higher the degree of coordination, the equation is

$$
\begin{aligned}
& C=4 \times\left\{\frac{h_{1} \times h_{2} \times h_{3} \times h_{4}}{\left(h_{1}+h_{2}+h_{3}+h_{4}\right)^{4}}\right\}^{1 / 4}, \\
& T=\alpha h_{1}+\beta h_{2}+\gamma h_{3}+\delta h_{4}, \\
& D=\sqrt{C \times T} .
\end{aligned}
$$

In the equation, $C$ is the degree of coupling; $h_{1}, h_{2}, h_{3}$, and $h_{4}$ are the comprehensive evaluation values of natural environment, humanity environment, living environment, 
TABLE 3: Consistency test of index level judgment matrix.

\begin{tabular}{lccccccccccc}
\hline Index level & $B_{1-6}$ & $B_{7-10}$ & $B_{11-12}$ & $B_{13-17}$ & $B_{18-23}$ & $B_{24-25}$ & $B_{26-29}$ & $B_{30-32}$ & $B_{33-36}$ & $B_{38-43}$ & $B_{44-48}$ \\
\hline$\lambda_{\max }$ & 6.5753 & 4.1855 & 2 & 5.2839 & 6.5354 & 2 & 4.0606 & 3.0536 & 4.2230 & 6.4209 & 5.0198 \\
$\mathrm{CR}$ & 0.0913 & 0.0695 & 0 & 0.0634 & 0.0850 & 0 & 0.0227 & 0.0516 & 0.0835 & 0.0668 & 0.0044 \\
\hline
\end{tabular}

and economic environment, respectively; $T$ is the coordination index; $\alpha, \beta, \gamma$ and $\delta$ are undetermined coefficients, this paper believes that the four systems are equally important, the value is $0.25 ; D$ is the coordination degree. This paper uses the median segmentation method [40]; the classification standard of coordination degree type is obtained (Table 4).

Sustainability of urban HS uses the sustainable growth rate to measure the sustainability of the urban HS to a high level of development. If the value is positive, its development is sustainable, and the sustainability intensity is positively correlated. With reference to the sustainable growth model proposed by the American financial scientist Robert Higgins and existing research [59], the equation is improved as

$$
\mathrm{SGR}=\frac{H_{t}-H_{t-1}}{H_{t-1}}
$$

In the equation, SGR is the sustainable growth rate and $H_{t}$ is the development level of the urban HS in a certain year.

3.3.3. Obstacle Model of Urban Human Settlements Sustainable Development. In order to grasp the causes of the differences in the development level of HS more accurately, pathological diagnosis and obstacles models should also be used to clarify the main obstacles affecting the quality of urban HS in order to make more targeted suggestions on the optimization of urban HS. The main idea of the obstacle degree model is to calculate the degree of restriction of the various indicators at various levels on the development of the HS. The larger the value, the stronger the obstacle to the development of the HS. The calculation equation is:

$$
\begin{aligned}
F_{j} & =W_{i} \times P_{i j}, \\
V_{j} & =1-K_{j}, \\
O_{j} & =\frac{F_{j} \times V_{j}}{\sum_{j=1}^{n} F_{j} \times V_{j}} \times 100 \% .
\end{aligned}
$$

In the equation, $F_{j}$ is the factor contribution degree; $W_{i}$ is the system weight; $P_{i j}$ is the weight of the $j$-th index in the $i$-th system; $V_{j}$ is the index deviation degree; $K_{j}$ is the standardized index value; and $O_{j}$ is the obstacle degree of each index.

\section{Results and Discussion}

First, equation (12) is used to calculate the development degree of the overall urban HS and each subsystem in the two cities from 2005 to 2018; equation (13) is used to calculate the coordination degree of the urban HS of the two cities; equation (14) is used to calculate the sustainability of the urban HS of the two cities. Then, 2005, 2010, 2015, and
TABle 4: The classification criteria of coordinative degree.

\begin{tabular}{lc}
\hline Coordination degree & Coordination level \\
\hline $0.000-0.099$ & Extreme disorder \\
$0.100-0.199$ & Serious disorder \\
$0.200-0.299$ & Moderate disorder \\
$0.300-0.399$ & Mild disorder \\
$0.400-0.499$ & On the verge of disorder \\
$0.500-0.599$ & Barely coordinated \\
$0.600-0.699$ & Primary coordination \\
$0.700-0.799$ & Intermediate coordination \\
$0.800-0.899$ & Good coordinated \\
$0.900-1.000$ & Quality coordination \\
\hline
\end{tabular}

2018 are selected as representatives, and the overall urban HS of the urban areas of the two cities and the development level of each subsystem are matched spatially, using the natural breakpoint method, the development of HS is divided into three levels of low, medium, and high. Finally, the main obstacle factors and obstacle degrees for the sustainable development of the urban HS of the two cities and each urban area are calculated by equation (15).

\subsection{Comparison of Sustainable Development Ability of Urban Human Settlements between Dalian and Kobe}

4.1.1. Comparison of Development Degree of Urban Human Settlements. The overall development level of the urban HS in Dalian and Kobe has shown a good upward trend. The development level of Kobe has always been higher than that of Dalian, but the development gap between the two cities has gradually narrowed (Figure 1). The development trend of the urban HS in Kobe has shown a steady and small increase. The development rate of urban HS has increased from 0.507 in 2005 to 0.576 in 2018, with an average annual growth rate of $0.997 \%$. The quality of the HS in Kobe has been increasing slowly from 2005 to 2014. This is the stage of urban economic recovery and stable life of residents after the reconstruction of the Great Hanshin Earthquake; in 2015, on the basis of the "Fifth Kobe Basic Plan" and the "Low Carbon, Natural Symbiosis and Recycling Society," it adjusted the urban spatial structure and industrial structure, created a comprehensive transportation environment by sea, land, and air, and promoted personnel exchanges and economic development to a new level. Through the establishment of "Regional Welfare Network Users" and "Employment Promotion Associations" to provide professional support to socially disadvantaged groups in all aspects, improve the peace of mind index, the quality of the HS is rapidly improved. The quality of the urban HS in Dalian has fluctuated upwards, and the increase is more obvious than that in Kobe. It has increased from 0.323 in 2005 to 0.509 in 2018 , with an average annual growth rate of $3.568 \%$. The 


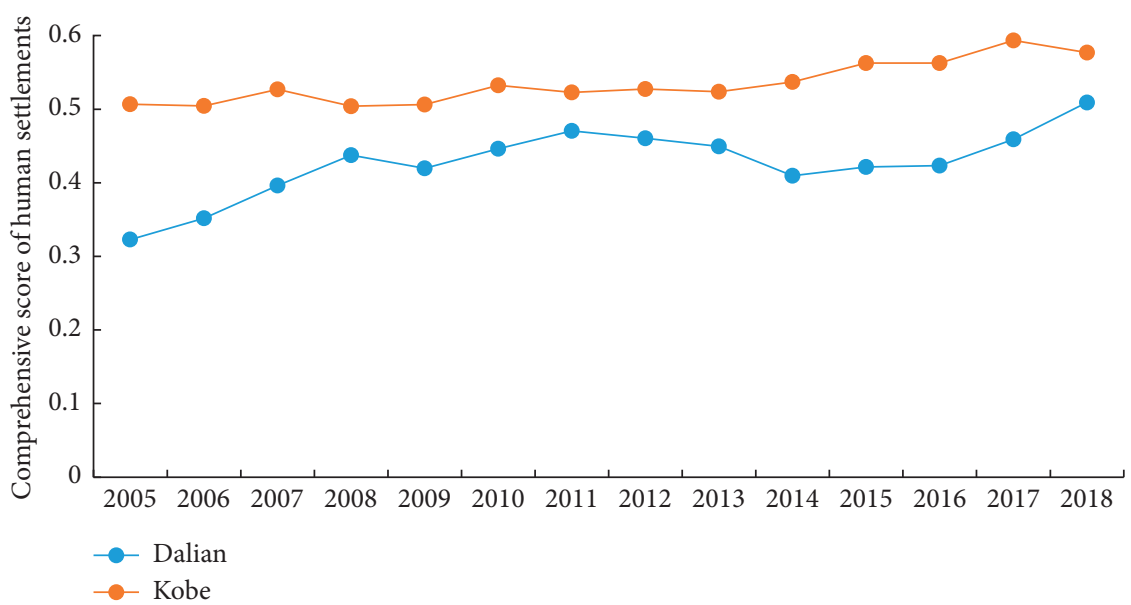

Figure 1: Development degree of urban human settlements in Dalian and Kobe from 2005 to 2018.

development of the HS in Dalian is roughly divided into three stages. The rapid development stage is from 2005 to 2011, the "Enriching People Project" during the "Eleventh Five-Year Plan" period has significantly improved the quality of life of residents in terms of income, housing, and social security. At the same time, it promoted the balanced development of compulsory education across the entire territory, investing heavily in emission reduction, and leaping development in transportation has resulted in an overall improvement in the quality of the HS; during the period of gradual decline from 2012 to 2014, Dalian's economic decline was severe during this period, the growth rate of GDP and fiscal revenue has dropped significantly, and fixed asset investment has shrunk, which also affected the ability to govern the ecological environment; resuming growth stage is from 2015 to 2018, when Dalian became a national comprehensive pilot city for new urbanization in 2015, and the comprehensive deepening of reforms in ecology, economy, culture, and society has once again improved the development level of the HS.

In terms of natural environment, thanks to Japan's advanced environmental awareness, the environmental conditions of Kobe have always been ahead of Dalian (Figure 2(a)). The natural environment of Kobe remains stable and good. Driven by the goal of "Building an Ecological and Livable City" in Dalian, the sustainable development level of the natural environment has risen in volatility, and the gap with Kobe has been greatly reduced. Dalian has certain advantages in topography, which is relatively flat and conducive to water and soil conservation and vegetation growth. Kobe's awareness of energy conservation and emission reduction in every detail of production and life gives it a strong advantage in terms of energy consumptions per GDP and air quality; at the same time, represented by the "Rokko Mountain Forest Improvement Strategy," "Basic Water Plan," and "2020 Kobe Biodiversity Plan," it will comprehensively enhance environmental protection awareness and establish a good ecological cycle system; the city's ecological zone has been expanded to 128 areas, and the green coverage of built-up areas and the per capita park area is 1.5 times that of Dalian; under the requirements of building a "Material Recycling Society," strict classification of waste and 3R (Reduce, Reuse, and Recycle) treatment have made it better in terms of the harmless treatment rate of domestic waste.

In terms of humanity environment, the level of sustainable development of humanities in Dalian is better than that of Kobe (Figure 2(b)). The development of humanity environment in Kobe is slow without any significant improvement. Although Dalian has experienced a phased decline, it has maintained an overall upward trend. In terms of demographic characteristics, due to the prolongation of average life-span in Kobe, the aging problem is serious, the aging rate is nearly twice that of Dalian, and the fertility rate is low; the population has been declining since 2012, when combined with population density and sex ratio, the population structure of Kobe is at a disadvantage. In terms of culture and innovation, Japan implemented nine-year compulsory education earlier, making Kobe's teaching resources more reasonable and complete, with higher per capita education expenditures and more public cultural institutions; in addition, the Kobe Government attaches great importance to technological development and makes full use of the advantages of " $K$ Computer" in the fields of drug research and development, semiconductor materials, etc., and accelerate the development of Kobe Technology. Dalian is accelerating the modernization of education. In 2018, per capita education expenditure increased to 9 times that of 2005, and the per capita collection of books tripled. Although the cultural resource base is relatively weak, the gap between the overall cultural environment and Kobe has narrowed significantly.

In terms of the living environment, although Dalian is in a good trend of continuous growth, the overall level of sustainable development of the living environment has been lagging behind Kobe (Figure 2(c)). The reason is that in terms of housing security, although the per capita housing area has been increasing and the housing price-to-income ratio has continued to decline in Dalian. Kobe has formulated housing development plans every five years to meet the different needs of residents in different periods. At the same time, it continues to enhance the building's seismic, 


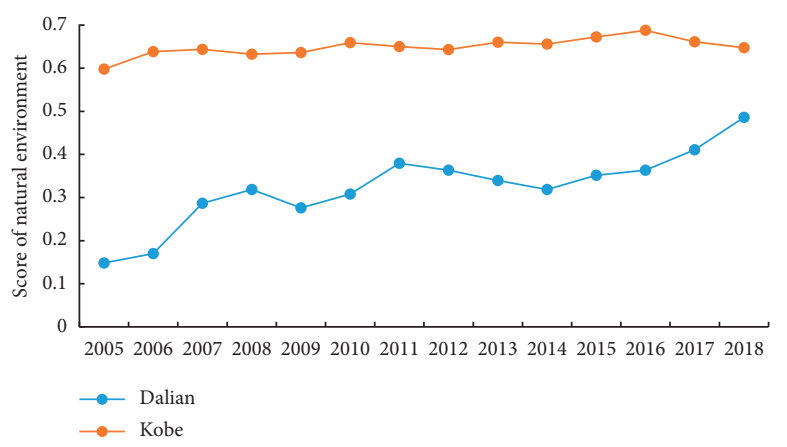

(a)

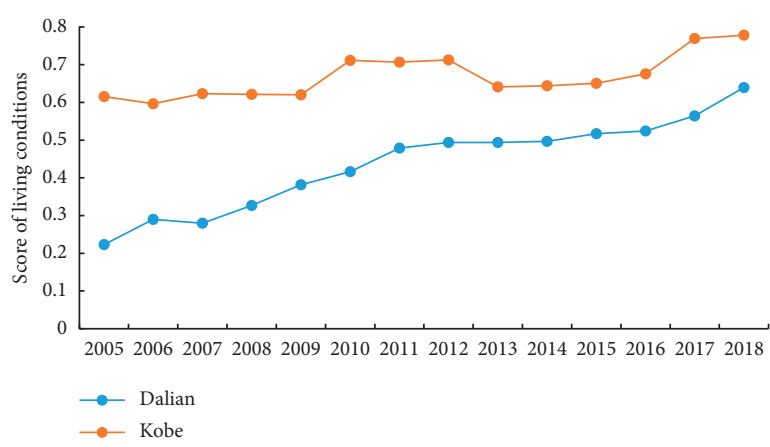

(c)

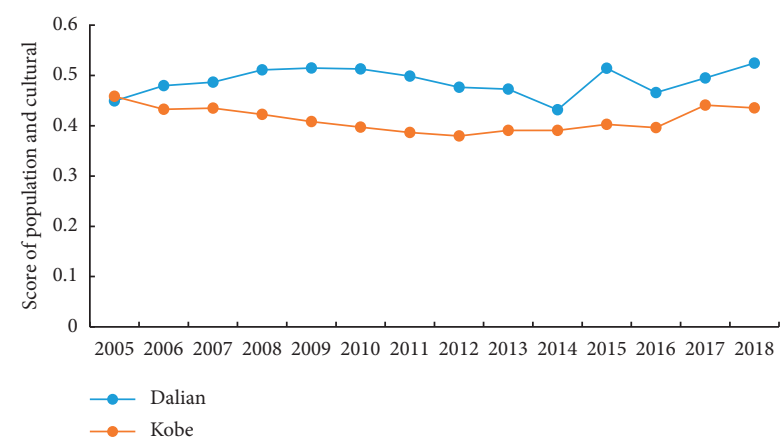

(b)

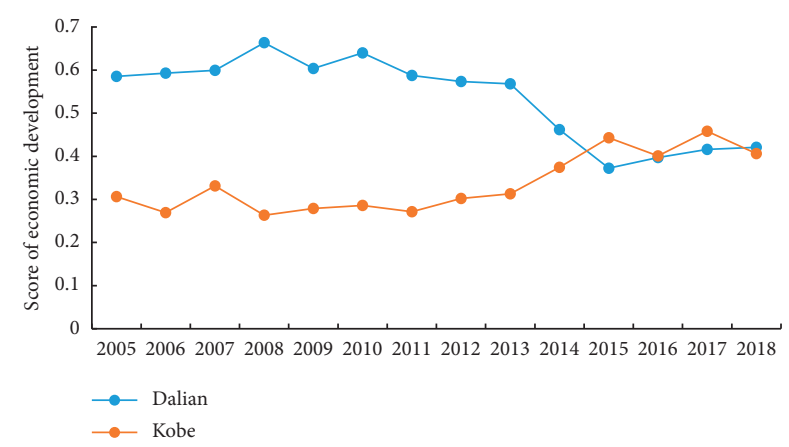

(d)

Figure 2: Development degree of the subsystems of urban human settlements in Dalian and Kobe from 2005 to 2018 . (a) Natural environment, (b) humanity environment, (c) living environment, and (d) economic environment.

fireproof, and waterproof capabilities. The two cities have comparable levels of development in municipal infrastructure. In terms of traffic facilities and safety, Kobe's road network is more reasonable, the road barrier-free design is more complete, the death rate of traffic accidents is lower, and the quality of travel is higher. In terms of public services, Kobe attaches great importance to the development of people-oriented and social justice, strengthens legislation, and has established a relatively developed public service system in areas such as sports and fitness, medical care, facilities for the elderly, and the disabled, which continuously promotes the sustainable development of the living environment.

In terms of economic environment, the overall level of sustainable economic development in Dalian is higher than that in Kobe (Figure 2(d)). Before 2013, the development levels of the two cities were quite different. However, as the quality of Dalian's economy continued to decline, Kobe rose steadily and surpassed in 2015 Dalian. Affected by the Great Hanshin Earthquake, Kobe has been committed to economic recovery. A large amount of finance has been used to support the lives of residents and help enterprises. The financial demand is dozens of times higher than usual. In addition, Kobe's serious aging problem has affected the supply of labor resources. The reduction in consumption also affects government investment and social savings; in 2014, through vigorously developing the medical industry, it formed "Japan's largest biomedical cluster," turning Hanshin Port into an "international container hub port," which strengthened international logistics competitiveness, and increased demand in overseas markets such as clothing, sake, and pearls and achieved rapid economic growth. Dalian has a good economic foundation. Before 2013, significant progress was made in transforming the economic growth mode and developing a brand economy, which resulted in faster growth in GDP, fiscal revenue, fixed asset investment, and per capita disposable income, far surpassing that of Kobe; after 2013, under the influence of the international financial crisis, wharf trade suffered huge losses, coupled with the lack of industrial innovation, and the economic level fell severely in a short period of time; until 2015, the pace of transformation and upgrading of traditional industries was accelerated to enhance the competitiveness of emerging industries, the economy came back rapidly. In terms of the supply of living material resources for residents, Dalian's per capita grain output and seafood output have always been far ahead of Kobe.

\subsubsection{Comparison of Coordination Degree of Urban Human} Settlements. As shown in Figure 3, the coordination degree of urban HS in Dalian and Kobe has shown a good upward trend. The interaction among the four systems continues to increase. The overall coordination degree of the development of HS in Kobe is higher than that of Dalian. The degree of coordination of urban HS in Kobe has risen steadily. In 2005 , the coordination degree was in the stage of primary, and the increase was significant in 2014, and it was stable at the stage of intermediate. After experiencing the devastating impact of the Great Hanshin Earthquake in 1995, Kobe 


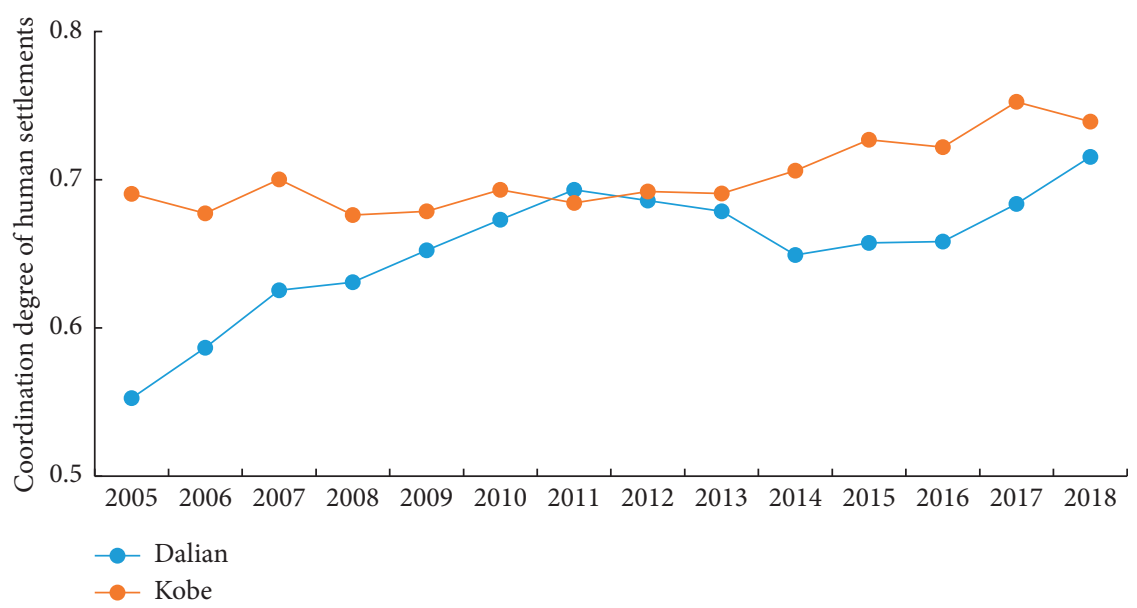

Figure 3: Coordination degree of urban human settlements in Dalian and Kobe from 2005 to 2018.

basically completed an innovative urban regeneration, the "Hyogo Phenomenon Project" in 2005. After that, the Kobe municipal government vigorously supports the economy and takes the residents as the main body to comprehensively improve the environmental construction, which makes the coordination degree of the HS in Kobe rise smoothly and steadily; after 2014, the booming economy of Kobe attracts talents and companies, and the government pays attention to the problem of population decline and aging, and it has issued policies to comprehensively guarantee birth and educate children, and strive to promote "Universal Design (UD)" to create an environment, buildings, services, etc. that are easy for anyone to use. It makes every effort to build a futureoriented city open to the world and promote the coordination of urban HS to an intermediate level of coordination. The coordination degree of Dalian's urban HS development has fluctuated upward. It was barely coordinated from 2005 to 2006 , and remained in the primary coordination stage from 2007 to 2017. However, the degree of coordination decreased from 2012 to 2014 and began to slowly rise in 2015. Until 2018 it developed to the stage of intermediate coordination. During the "Eleventh Five-Year Plan" period, Dalian has undergone major changes in its urban spatial layout and industrial layout, and its infrastructure and greening levels have rapidly improved. During this period, it has been awarded the titles of "National Civilized City" and "International Garden City," which realized the coordinated growth of the HS. From 2012 to 2014, Dalian's economic development was undergoing transformation, economic development was lagging behind, and land, water and energy resources were relatively tight, which made it difficult for the natural and economic environment to improve simultaneously with population quality and living conditions; after 2015, the "Belt and Road" initiative and a new round of revitalization of the old northeast industrial base have brought new opportunities for the development of Dalian, and promoted a slight increase in the coordination of the urban HS subsystem.

4.1.3. Comparison of Sustainability of Urban Human Settlements. As shown in Figure 4, the sustainability of the urban HS in Dalian and Kobe is in a fluctuating development state, and the sustainability is relatively unstable. The average sustainable growth rate of the HS in Dalian is higher than that in Kobe. During the study period, the sustainable growth rate of HS in Kobe was negative in nearly half of the years, and the HS was in an unsustainable state. Before 2014, Kobe was committed to economic revival, but the growth rate was slow, which restricts the improvement of urban infrastructure and public service. Coupled with social factors such as population aging, it resulted in a low sustainable growth rate of urban HS; after 2014, with the United Nations' 2030 Agenda for Sustainable Development, Japan has re-formulated its development outline in various fields based on its national conditions, such as the Environmental Basic Plan and the Basic Plan for Establishing a Circular Society Development. On this basis, it will further improve the urban ecological environment, develop the natural history tourism and cultural industry, and strengthen technological innovation, with a view to realizing "Smart Society 5.0" as soon as possible, which gives full play to the advantages of youth and female researchers and strives to achieve a sustainable HS with strong resilience to disasters, so that the sustainability of urban HS has improved, but in terms of comprehensive poverty alleviation and the utilization of marine resources, the performance is insufficient, and there is still a distance from the goal of sustainable and stable development. The sustainable growth rate of Dalian's HS continued to decline from 2006 to 2011 but remained basically positive, indicating that even if sustainability weakened, the HS was in a state of sustainable development; from 2012 to 2014, the sustainable growth rate of HS is negative. The reason is that under the influence of global trade imbalance, the downward pressure on Dalian's economy has increased, while restricting the development of other aspects of the HS, it resulted in poor continuity and stability of the development of the HS in an unsustainable state. After 2015, the sustainable growth rate of the HS has increased to a positive value. During this period, under the guidance of the national supply-side structural reform, Dalian has made every effort to promote citywide urbanization development and 


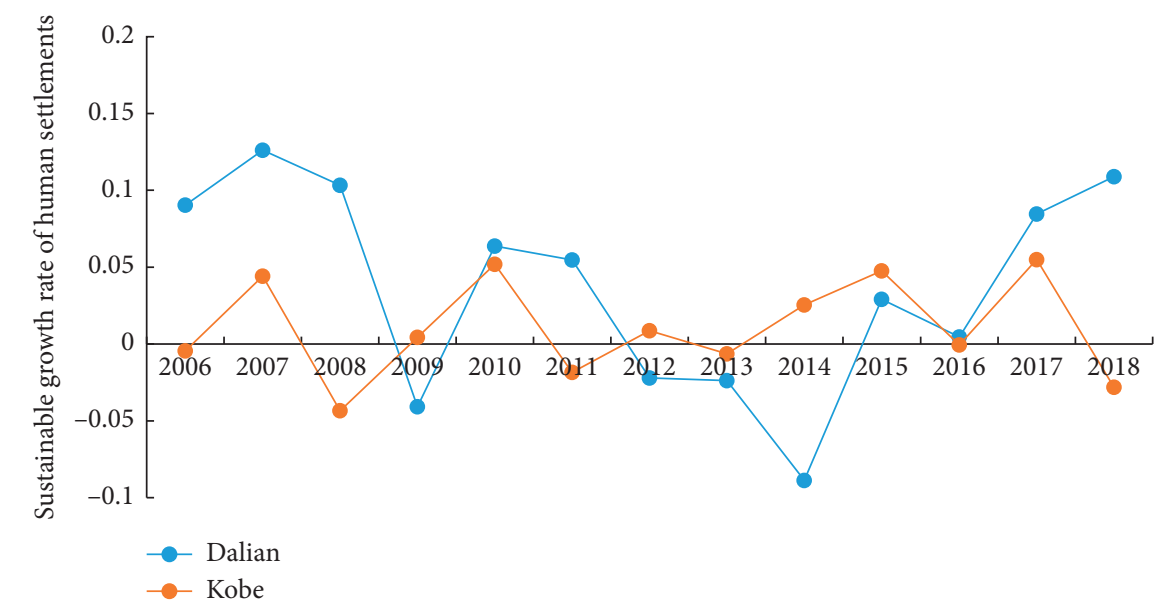

FIgURE 4: Sustainability of urban human settlements in Dalian and Kobe from 2006 to 2018.

at the same time striven to build a green, low-carbon, resource-efficient city, so that the sustainability of the development of the HS was enhanced and in a sustainable state.

\subsection{Spatial-Temporal Differentiation and Influencing Factors of Sustainable Development Ability of Urban Human Settlements in Dalian}

4.2.1. Spatial Characteristics of Sustainable Development Ability of Urban Human Settlements. From 2005 to 2018, the overall quality of the development of the urban HS in Dalian gradually improved, with a pattern of high in the south and low in the north (Figure 5). The quality of the HS in Zhongshan District and Xigang District has always been in a leading position. Zhongshan District is the financial, commercial, and tourist center of Dalian. Due to the early start of regional construction, it has strong economic strength and excellent ecological environment. Xigang District is the administrative and cultural center of Dalian and the first fullscale provincial-level modern service industry cluster in the coastal economic belt of Liaoning. Lushunkou District has a good ecological environment and rich tourism resources. It is an important transportation hub in Northeast China. Under the guidance of the goal of building a "green economic zone," the quality of HS has been raised to a high level of development. Shahekou District has been transformed from an industrial area to a commercial area, relying on the Xinghai Bay Financial and Business District to enhance the regional economy, while continuously upgrading and transforming old communities, and the quality of the HS has been maintained at a medium level. Jinzhou District is an important part of Dalian's new urban area. It has a solid foundation for opening up. However, due to the continuous adjustment of the urban spatial layout, the pace of improvement of the HS is slow, resulting in a low level of the HS. Ganjingzi District implemented the "removal of towns to build streets" in 2007. Due to the low level of urbanization and late regional construction, the development of its HS has always been at a medium or low level of development.
The level of the natural environment development in Dalian has generally risen (Figure 6). Zhongshan District, Xigang District, and Lushunkou District have a higher degree of greening. In addition, Lushunkou District is also a national-level scenic spot, nature reserve, and ecological demonstration area, while Ganjingzi District and Jinzhou District focus on regional construction and industrial development; they also put pressure on the ecological environment, causing the natural environment to be at a disadvantage. The quality of the humanity environment presents a spatial pattern of "high on both sides and low in the middle" (Figure 7). The population density of Lushunkou District and Jinzhou District is moderate, the aging rate is low, the per capita education and cultural resources are abundant, and the humanity environment is at a high level of development; Xigang District is home to Dalian library, science and technology museum, etc.; cultural and creative industries are booming there, and the humanity environment is constantly improving to a high level of development; Zhongshan District is the old city of Dalian, with a high population density and a high aging rate, which affects the overall humanity environment; with the development of high-tech industries, Ganjingzi District has attracted many young talents, and the quality of humanity has improved from low to medium level significantly; Shahekou District has a high population density and a high aging rate, with a relatively large proportion of people enjoying subsistence allowances, and the shortage of per capita educational resources has led to a low-level development of the humanity environment The spatial-temporal pattern of the living environment quality is relatively stable, showing a spatial pattern of high in the south and low in the north (Figure 8). The quality of the living environment in Ganjingzi District and Jinzhou District has always been at a low level of development, mainly due to incomplete infrastructure and public service facilities and low living convenience. The development level of the economic environment presents the spatial characteristics of "high in the east and low in the west" (Figure 9). With the advantages of the financial and commercial center, the economic level of Zhongshan District has always been far ahead; the Xigang 


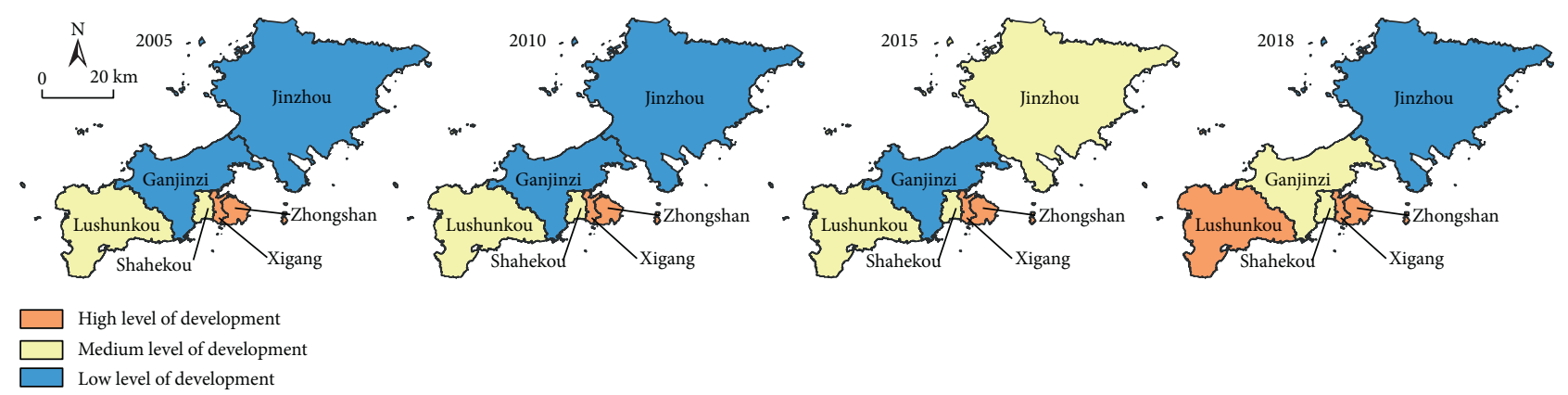

FIgURE 5: Spatial differentiation of the development level of urban human settlements of Dalian in 2005, 2010, 2015 , and 2018.

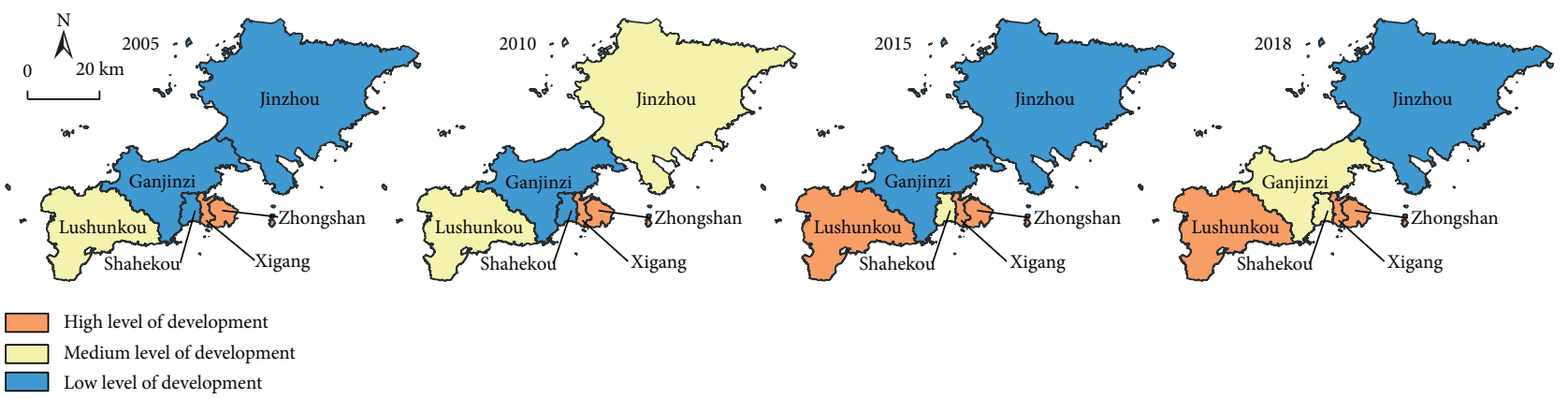

FiguRe 6: Spatial differentiation of the natural subsystem development level of urban human settlements of Dalian in 2005, 2010, 2015, and 2018.

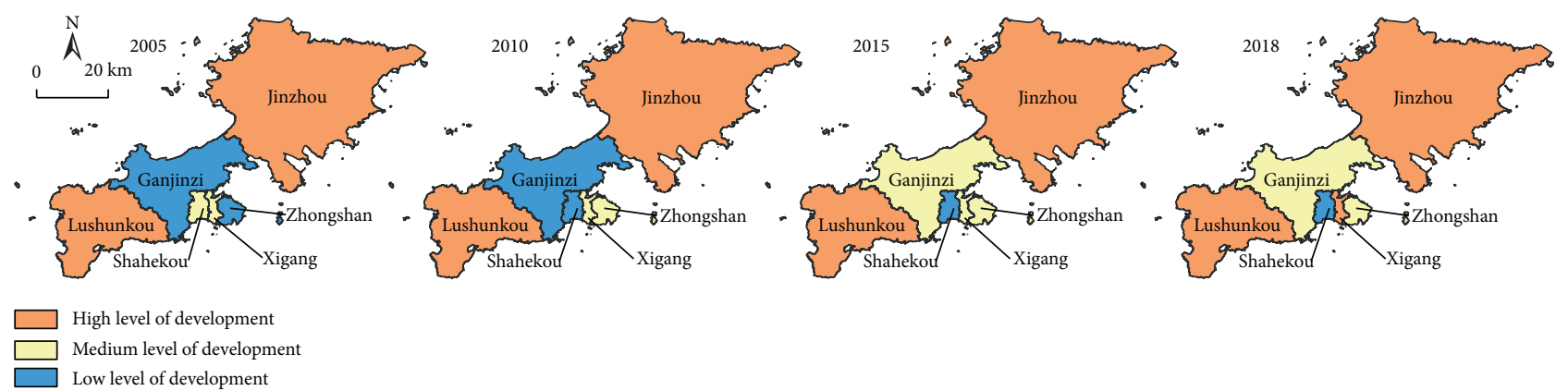

FiguRE 7: Spatial differentiation of the humanity subsystem development level of urban human settlements of Dalian in 2005, 2010, 2015, and 2018 .

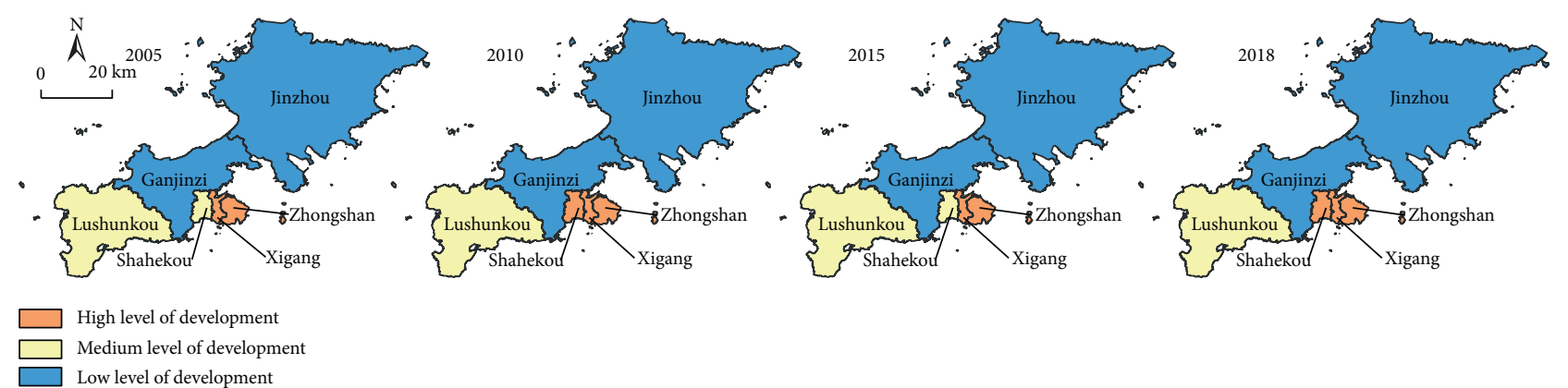

FIGURE 8: Spatial differentiation of the residential subsystem development level of urban human settlements of Dalian in 2005, 2010, 2015, and 2018.

District continues to give full play to the advantages of the administrative center to develop the characteristic business and tourism economy. The level has developed from a medium level to a high level; Jinzhou District vigorously develops equipment manufacturing industry, which is a hot spot for foreign investment, and its economy has developed 


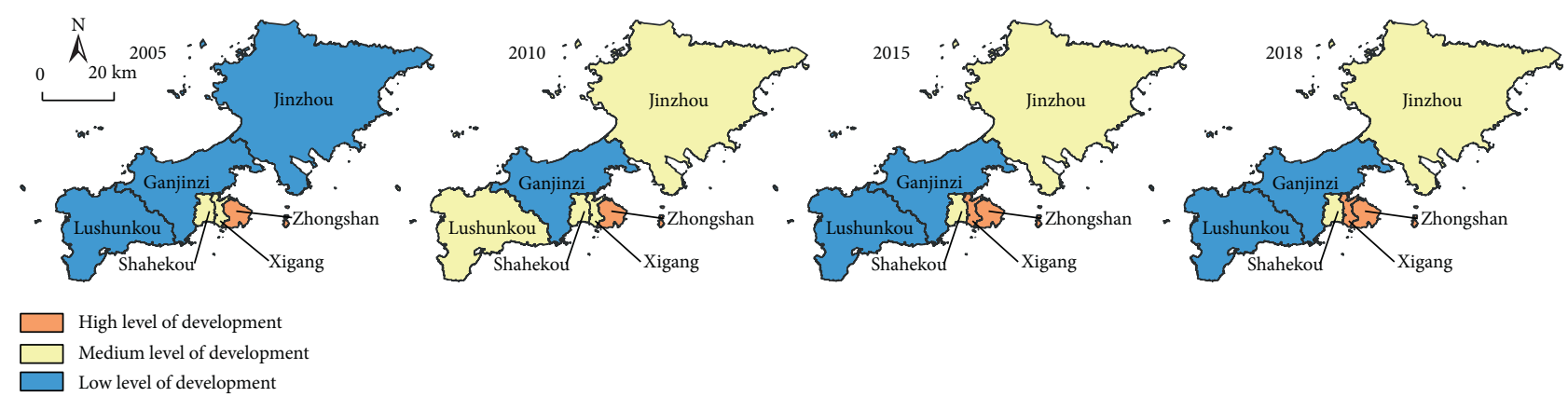

Figure 9: Spatial differentiation of the economic subsystem development level of urban human settlements of Dalian in 2005, 2010, 2015, and 2018.

rapidly from a low level to a medium level; the economic foundation of Ganjingzi District is poor, the industrial structure is unreasonable, and the regional development is extremely uneven. In addition, the area is large and the radiation effect is weak, and the economy has been in a state of low development.

4.2.2. Obstacle Factors for the Sustainable Development Ability of Urban Human Settlements. Table 5 lists the obstacles and their degree of obstacles to the sustainable development of the HS in Dalian, which ranked the top 6 in 2005, 2010, 2015, and 2018. The table shows that the main obstacles to the sustainable development of the HS are caused by economy-nature transformed into economy-nature-culture-public services. From 2005 to 2018, among the main obstacles, the Engel coefficient, GDP per capita, the proportion of tertiary industry in GDP, and the green coverage of built-up areas have reduced resistance to the development of the human settlements, whereas per capita disposable income, the ratio of teachers and students in primary and secondary schools, and the number of doctors per 10,000 people have increased the obstacles to the development of the HS. The air quality index and per capita water resources have shown fluctuations. It shows that the ecological environment has improved. Residents' requirements for the HS have shifted from the material level to the spiritual civilization level, and the consumption structure has changed from survive to enjoyment. For the sustainable development of the urban HS in Dalian, in terms of natural environment, it improves the level of urban greening and promotes resource conservation and utilization; in the humanity environment, it improves the allocation of educational resources and the level of social civilization; in the living environment, it increases the quantity and quality of public services; in the economic environment, it promotes the healthy development of the economy and pay attention to the lives of residents quality.

There are also differences in the main obstacle factors in different districts (Table 6). In 2005, the main obstacle factors in the six urban areas of Dalian were relatively consistent, which focused on urban greening, municipal infrastructure, and economic development quality; in 2018, the main obstacle factors in Dalian's urban areas were quite different, the economic volume barriers of Zhongshan
District have decreased, the obstruction degrees in the aging rate, the ratio of teachers and students in primary and secondary schools, the proportion of science and technology expenditures, and the number of 10,000-person stadiums have all increased; the impact of the economic scale of Xigang District has decreased, and the impact of demographic characteristics has increased; it shows that although the HS of Zhongshan District and Xigang District is relatively high, they still need to improve population quality, increase investment in science, education, culture, and technological innovation. In addition, it is necessary to pay attention to the problem that the large population makes the infrastructure per capita small. The main obstacle factors in Shahekou District are population characteristics, urban greening, and economic development; the main obstacle factors in Ganjingzi are relatively scattered; the main obstacle factors in Lushunkou District come from the level of economic scale; the obstacles to economic development in Jinzhou District are reduced, and the degree of obstacles to urban greening and public services has increased. The development level of the HS in these areas is not high. While focusing on economic development, it is necessary to balance the ecological environment and promote the quality of urban public services.

\subsection{Spatial-Temporal Differentiation and Influencing Factors of Sustainable Development Ability of Urban Human Settlements in Kobe}

4.3.1. Spatial Characteristics of Sustainable Development Ability of Urban Human Settlements. From 2005 to 2018, the overall development quality of the urban HS in Kobe showed a steady upward trend, with a spatially high level of development in the southeast, radiating to the surroundings (Figure 10). The HS of Chuo-ku and Higashinada-ku always has strong advantages. Chuo-ku is the commercial, entertainment, administrative center, and transportation hub of Kobe. It is rich in tourism resources and is an area with concentrated urban functions; Higashinada-ku has a better natural environment, and its reconstruction was fast after the Hanshin earthquake, the regional industry there is rich, and the degree of openness is relatively high. Residents consider it as a place of residence that they want to continue living or want to return to. The urbanization of Hyogo-ku 
TABLE 5: The obstacle indicators and degree of the sustainable development of urban human settlements of Dalian in 2005, 2010, 2015, and 2018.

\begin{tabular}{ccccccc}
\hline Year & 1 & 2 & 3 & 4 & 5 & 6 \\
\hline 2005 & $B_{46}(6.16)$ & $B_{38}(5.99)$ & $B_{7}(5.55)$ & $B_{41}(4.87)$ & $B_{6}(4.76)$ & $B_{12}(4.18)$ \\
2010 & $B_{46}(7.36)$ & $B_{38}(6.85)$ & $B_{12}(6.51)$ & $B_{41}(6.27)$ & $B_{45}(6.05)$ & $B_{6}(4.82)$ \\
2015 & $B_{19}(8.50)$ & $B_{35}(6.63)$ & $B_{45}(6.24)$ & $B_{46}(6.10)$ & $B_{12}(5.52)$ & $B_{32}(4.96)$ \\
2018 & $B_{19}(9.68)$ & $B_{35}(8.04)$ & $B_{45}(7.55)$ & $B_{6}(7.34)$ & $B_{44}(7.28)$ & $B_{12}(6.51)$ \\
\hline
\end{tabular}

TABLE 6: The obstacle indicators and degree of the sustainable development of urban human settlements of different districts of Dalian in 2018.

\begin{tabular}{lcccccc}
\hline District & 1 & 2 & 3 & 4 & 5 \\
\hline Zhongshan & $B_{16}(9.39)$ & $B_{19}(8.50)$ & $B_{39}(7.43)$ & $B_{23}(7.27)$ & $B_{45}(5.78)$ & $B_{33}(5.46)$ \\
Xigang & $B_{16}(8.47)$ & $B_{15}(7.67)$ & $B_{39}(6.71)$ & $B_{38}(6.56)$ & $B_{45}(5.20)$ & $B_{47}(5.16)$ \\
Shahekou & $B_{39}(7.73)$ & $B_{7}(6.70)$ & $B_{38}(6.12)$ & $B_{16}(5.99)$ & $B_{13}(5.94)$ & $B_{8}(4.86)$ \\
Ganjingzi & $B_{38}(7.63)$ & $B_{41}(6.91)$ & $B_{19}(6.04)$ & $B_{45}(5.91)$ & $B_{7}(4.84)$ & $B_{34}(4.82)$ \\
Lushunkou & $B_{38}(7.96)$ & $B_{45}(7.74)$ & $B_{39}(7.20)$ & $B_{1}(6.30)$ & $B_{41}(6.16)$ & $B_{40}(5.22)$ \\
Jinzhou & $B_{7}(7.41)$ & $B_{38}(6.65)$ & $B_{39}(6.47)$ & $B_{8}(5.66)$ & $B_{33}(5.53)$ & $B_{1}(4.97)$ \\
\hline
\end{tabular}

developed earlier. After 2010, it has formed a spatial structure with emphasis on the ecological environment in the north, commercial and cultural activities in the middle, and industry in the south, making the quality of the HS from a medium level to a high level of development. Nada-ku makes full use of natural, historical, and cultural advantages, vigorously promotes the tourism industry, builds a commercial and residential complex, and continuously improves the quality of HS to a high-level development stage. Tarumi$\mathrm{ku}$ is dominated by residential land, with complete infrastructure, sitting on the Akashi Strait Bridge, connecting Awaji Island and the four countries of Honshu, promoting cultural exchanges and economic development, and coupled with a good ecological environment, the HS has moved from a low level to a medium development level earlier. In Nishi$\mathrm{ku}$, the development of the new town and industrial park has driven other improvements; Nagata-ku has made full use of open space in recent years and eliminated old houses, and the cultural and creative industries have attracted many young creators and artists. The quality of the HS in the two districts has been continuously improved from a low level to a medium level. The construction of the Kita-ku and Suma$\mathrm{ku}$ started late, the development level is low, the economic foundation is weak, and the transportation is inconvenient, so that the HS has been at a low level of development.

The overall development level of the natural environment in Kobe continues to rise, showing a spatially differentiated pattern of "roofing" (Figure 11). The level of sustainable development of natural environment: Central $>$ West $>$ Southeast. The Suma-ku and the Kita-ku are affected by the low level of urbanization. The environmental pressure is small. The two districts retain a large area of rural green space, and there are many parks in the Suma$\mathrm{ku}$; Kita-ku has natural scenery represented by Arima Hot Springs, and it was the first to implement container packaging classification in 2008, and the natural environment of the two districts has been at a high level of development; Nishi-ku and Tarumi-ku vigorously protect the rural scenery and coastal environment, and they plant flowers to improve the level of regional greening, so that the quality of the natural environment has increased from a medium level to a high level; due to the relatively high level of regional development, Chuo-ku and Higashinada-ku have severely damaged the ecological environment and is in a low-level development state. Although the overall humanity environment of Kobe has improved, the progress has not been obvious; relatively speaking, the development level of the southeast is relatively high (Figure 12). The development level of the humanity environment of Higashinada-ku is always high; this is mainly due to the high migration rate and the young population. At the same time, there are many universities and cultural art galleries here, with a high population quality and a good cultural atmosphere; the Chuo-ku initially has a high aging rate, and with the development of the region, it continues to attract young people and high-quality talents, and the quality of the humanity environment continues to improve; Kita-ku and Suma-ku have low population density, low education level, and poor educational resources, making the humanity environment lagging behind. The living environment of Kobe is improving steadily, and the high-quality development areas of the living environment are mainly concentrated in the southeast (Figure 13). Chuo-ku, Higashinada-ku, and Hyogo-ku have complete infrastructure, high quality of public services, convenient transportation, and the living environment is always in a leading state; the northern part of Nagata-ku continues to develop into a residential area for IT professionals, and with the development of the industrial park in Nishi-ku, the infrastructure is constantly improved, which promotes the development of the living environment of the two districts from low to medium level; as newly developed residential areas, Suma-ku and Kita-ku are not mature enough with inconvenient traffic and relatively poor public security, resulting in a disadvantaged living environment. The economic environment of Kobe is on a rising trend (Figure 14). Chuo-ku relies on the advantages of commercial and entertainment centers, Higashinada-ku takes advantage of the wine industry and the coastal 


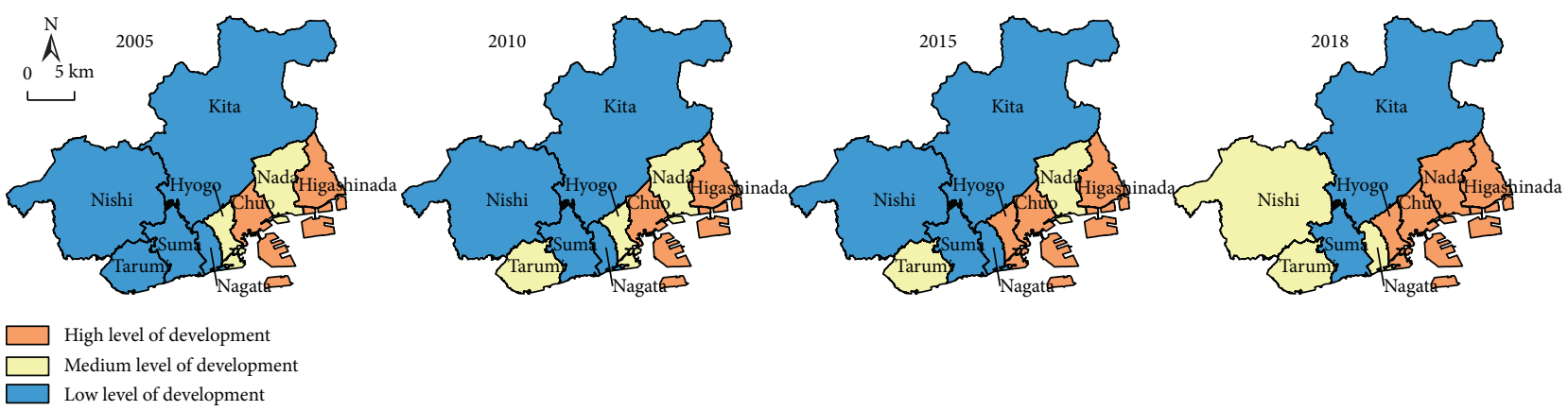

Figure 10: Spatial differentiation of the development level of urban human settlements of Kobe in 2005, 2010, 2015 , and 2018.

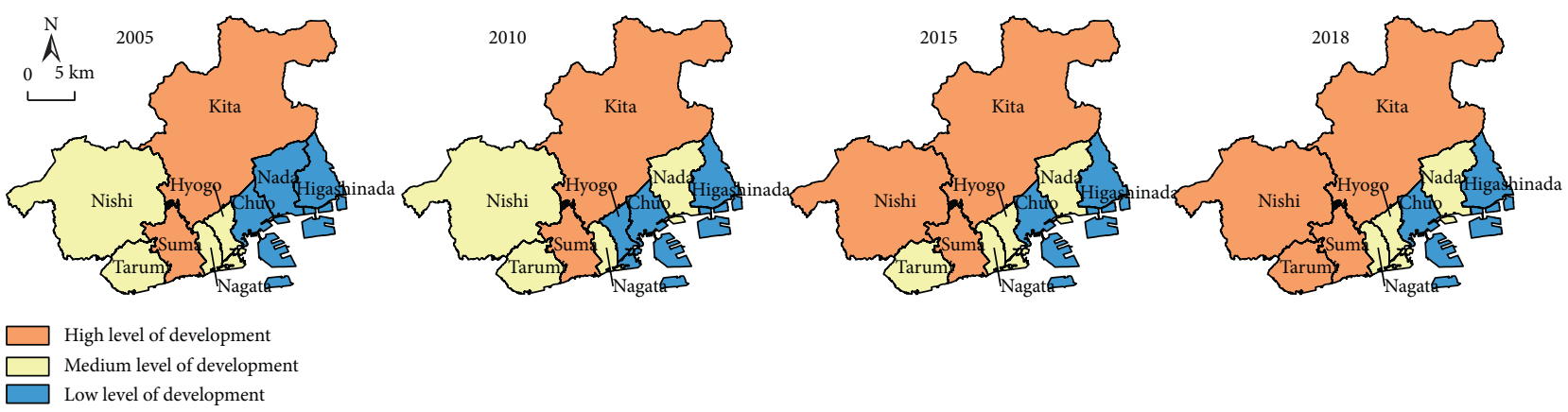

FIGURE 11: Spatial differentiation of the natural subsystem development level of urban human settlements of Kobe in 2005, 2010, 2015, and 2018.

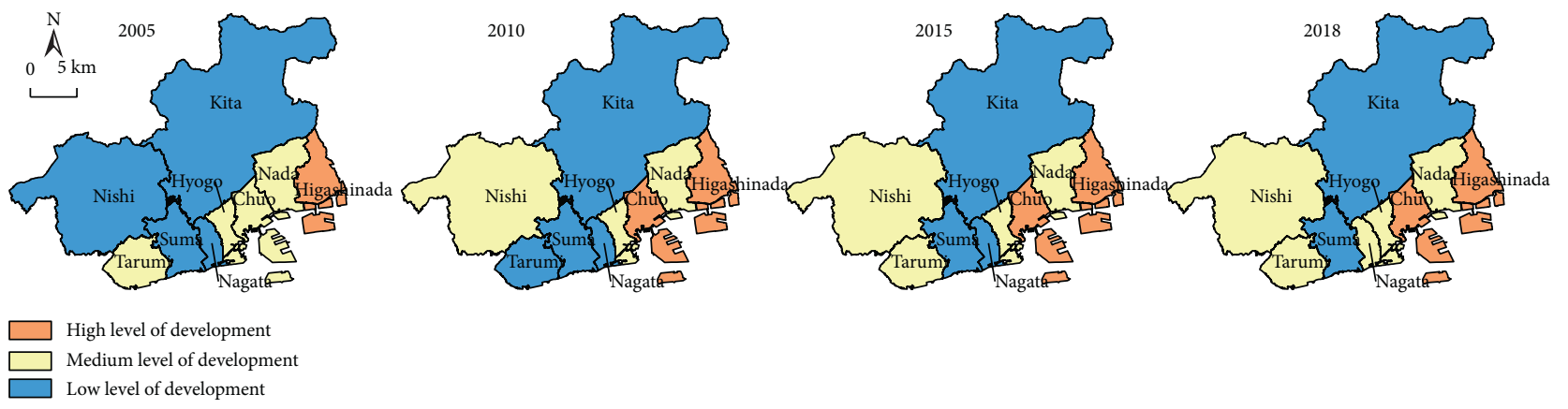

Figure 12: Spatial differentiation of the humanity subsystem development level of urban human settlements of Kobe in 2005, 2010, 2015, and 2018.

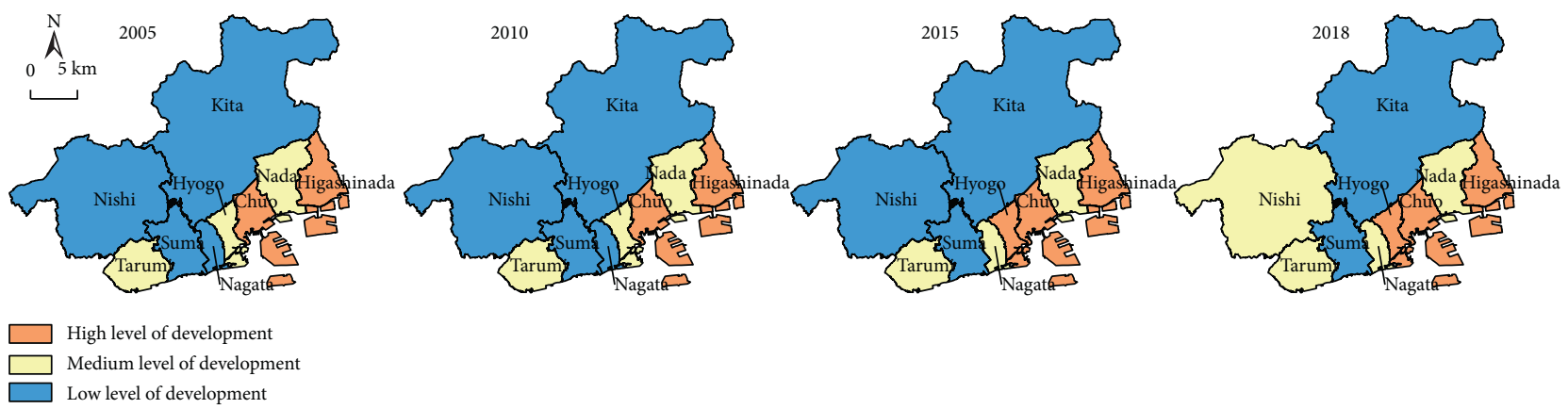

FIGURE 13: Spatial differentiation of the residential subsystem development level of urban human settlements of Kobe in 2005, 2010, 2015, and 2018. 


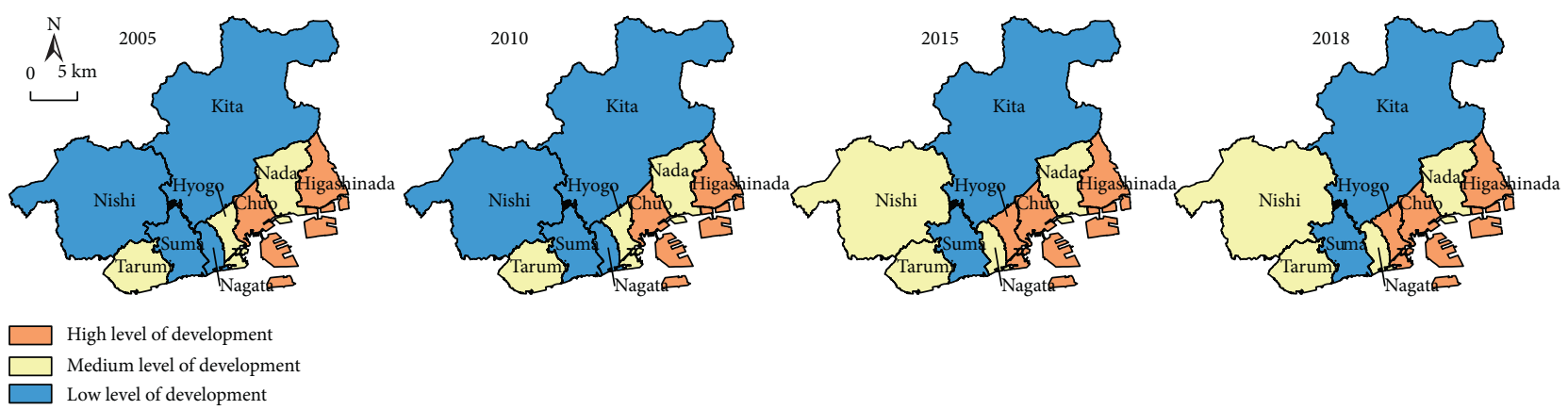

FIGURE 14: Spatial differentiation of the economic subsystem development level of urban human settlements of Kobe in 2005, 2010, 2015, and 2018.

industrial zone, and the Hyogo-ku vigorously develops commercial streets, which has kept the economic development in a good state; Nada-ku and Tarumi-ku develop tourism economy, and the economic environment has always been maintained at a medium level of development; the rapid development of cultural and creative industries in Nagata-ku and the industrial park in Nishi-ku have promoted the economic environment of the two districts from a low level to a medium level of development; the economic foundation of Suma-ku and Kita-ku is relatively poor, and the primary industry is the leading industry, which makes economic growth slow and the level of economic development low.

4.3.2. Obstacle Factors for the Sustainable Development Ability of Urban Human Settlements. It can be seen from Table 7 the top 6 obstacles to sustainable development of HS in Kobe in 2005, 2010, 2015, and 2018 and their degree of obstacles. Great changes were made from 2005 to 2010. The obstacles to sustainable development of the HS in 2005 were concentrated on economic growth, education and urban greening, and the obstacles in 2010 were concentrated on the level of economic development and demographic characteristics, the indicators that hinder the development of the HS in Kobe are relatively stable in 2015-2018, mainly focusing on the natural environment, demographic characteristics, and tertiary industry's share of GDP. Among them, the proportion of the added value of the tertiary industry has dropped slightly, the obstacles to the aging rate and the natural growth rate of the population continue to rise, they all indicate that the quality of the ecological environment, the economy and the quality of life are steadily improving, and the problem of population structure has become more and more serious, which become a key factor hindering the sustainable development of HS. The sewage treatment rate has a greater hindrance, mainly due to the slight decrease in the sewage treatment rate of Kobe in recent years. High relief degree of land surface can lead to soil erosion and affect urban construction and economic development, and it is also the main factors hindering sustainable development. In order to improve the sustainable development of the HS in Kobe, it is necessary to promote the coordinated and
TABle 7: The obstacle indicators and degree of the sustainable development of urban human settlements of Kobe in 2005, 2010, 2015, and 2018.

\begin{tabular}{|c|c|c|c|c|c|c|}
\hline Year & 1 & 2 & 3 & 4 & 5 & 6 \\
\hline 2005 & $B_{38}(9.25)$ & $B_{39}(6.94)$ & $B_{21}(5.39)$ & $\begin{array}{c}B_{19} \\
(5.36)\end{array}$ & $\begin{array}{c}B_{8} \\
(5.14)\end{array}$ & $\begin{array}{c}B_{15} \\
(5.10)\end{array}$ \\
\hline 2010 & $B_{38}(6.01)$ & $B_{41}(5.84)$ & $B_{13}(5.57)$ & $\begin{array}{c}B_{16} \\
(5.24)\end{array}$ & $\begin{array}{c}B_{17} \\
(5.15)\end{array}$ & $\begin{array}{c}B_{15} \\
(4.73)\end{array}$ \\
\hline 2015 & $B_{16}(8.20)$ & $B_{14}(6.80)$ & $B_{9}(6.25)$ & $\begin{array}{c}B_{41} \\
(5.25)\end{array}$ & $\begin{array}{c}B_{15} \\
(5.04)\end{array}$ & $\begin{array}{c}B_{1} \\
(4.86)\end{array}$ \\
\hline 2018 & $B_{16}(10.51)$ & $B_{14}(9.72)$ & $B_{9}(6.09)$ & $\begin{array}{c}B_{15} \\
(5.90)\end{array}$ & $\begin{array}{c}B_{41} \\
(5.65)\end{array}$ & $\begin{array}{c}B_{1} \\
(5.15)\end{array}$ \\
\hline
\end{tabular}

healthy development of industries, stimulate the potential and vitality of economic development, take into account the effective prevention and control of regional pollution, pay attention to population issues, effectively increase the fertility rate of residents, and promote population balance.

There are also differences in the main obstacle factors in different districts (Table 8). Regions with higher quality of HS have strong advantages in terms of economic foundation, infrastructure, and public service levels, and the obstacles are generally lower than other regions, such as Chuo-ku and Higashinada-ku, due to population agglomeration and the imbalance of the population structure, the shortage of per capita public service resources, shortage of education resources, and relatively high housing prices are the biggest obstacles to the sustainable development of the HS. In addition, the topography of Higashinada-ku is also the main factor hindering regional development. Due to the early start of regional construction in Hyogo-ku, Nada-ku, and Tarumi-ku, the infrastructure is becoming perfect; however, the aging problem has gradually become prominent, the degree of barriers to economic quality is gradually decreasing, and the barriers to the ratio of teachers and students in primary and secondary schools and the number of hospital beds for 10,000 people are gradually increasing. This shows that while improving economic strength, we must pay attention to the quality and quantity of public services. The quality of $\mathrm{HS}$ in the Nishi-ku, Nagata-ku, Suma-ku, and Kita-ku is relatively poor. Although the ecological environment has strong advantages, the quality 
TABLE 8: The obstacle indicators and degree of the sustainable development of urban human settlements of different districts of Kobe in 2018.

\begin{tabular}{lccccrc}
\hline District & 1 & 2 & 3 & 4 & 5 \\
\hline Higashinada & $B_{19}(10.45)$ & $B_{34}(9.66)$ & $B_{13}(6.72)$ & $B_{16}(5.87)$ & $B_{25}(5.12)$ & $B_{1}(4.97)$ \\
Nada & $B_{41}(10.45)$ & $B_{1}(9.66)$ & $B_{38}(6.72)$ & $B_{19}(5.87)$ & $B_{34}(5.12)$ & $B_{39}(4.79)$ \\
Chuo & $B_{19}(11.01)$ & $B_{16}(10.19)$ & $B_{33}(7.09)$ & $B_{25}(6.19)$ & $B_{15}(5.40)$ & $B_{17}(5.05)$ \\
Hyogo & $B_{16}(10.39)$ & $B_{13}(9.61)$ & $B_{39}(6.68)$ & $B_{19}(5.83)$ & $B_{34}(5.23)$ & $B_{14}(5.10)$ \\
Kita & $B_{41}(11.07)$ & $B_{38}(10.24)$ & $B_{45}(7.12)$ & $B_{16}(6.22)$ & $B_{1}(5.43)$ & $B_{17}(5.08)$ \\
Nagata & $B_{38}(10.10)$ & $B_{41}(9.35)$ & $B_{16}(6.50)$ & $B_{13}(5.86)$ & $B_{42}(5.68)$ & $B_{14}(4.96)$ \\
Suma & $B_{41}(11.68)$ & $B_{38}(10.81)$ & $B_{16}(7.52)$ & $B_{34}(6.56)$ & $B_{15}(5.73)$ & $B_{37}(5.36)$ \\
Tarumi & $B_{41}(10.61)$ & $B_{16}(9.81)$ & $B_{13}(6.83)$ & $B_{34}(5.96)$ & $B_{19}(5.20)$ & $B_{38}(4.86)$ \\
Nishi & $B_{38}(10.58)$ & $B_{40}(9.79)$ & $B_{41}(6.81)$ & $B_{16}(5.94)$ & $B_{19}(5.33)$ & $B_{15}(5.19)$ \\
\hline
\end{tabular}

of economic development is the biggest obstacle to regional development, and the degree of obstacles has increased to varying degrees. Its weak economic foundation and unbalanced industrial structure have led to a low standard of living of residents, a continuous outflow of talents, and an increase in the aging rate. At the same time, it also restricts the improvement of regional supporting facilities.

\section{Conclusion and Policy Implications}

5.1. Conclusion. With the global focus on sustainable development, the sustainable development ability of urban HS provides new directions for urban construction. However, the empirical analysis in this field, especially the comparative analysis among transnational cities, is still insufficient. In this paper, it chooses cities that are both close to the mountains and the sea-Dalian, China, and Kobe, Japan. Under the concept of sustainable development, first, an indicator system is built for the sustainable development of HS based on SDGs, and then from the perspective of the overall development level of the urban HS, the mutual coordination among the various subsystems, and the sustainability of the sustainable growth rate of the HS, the sustainable development ability of the urban HS in Dalian and Kobe from 2005 to 2018 were comparatively analyzed, and the strengths and weaknesses of each city were identified; it separately analyzed the spatial evolution pattern of the sustainable development level of the HS in each city, and its obstacle factors and degree of obstacles. This paper can provide methodological reference for quantitative analysis of the sustainability of HS and at the same time provide reference for scientific planning and improvement of urban HS quality and sustainable development ability. The main conclusions of this research are as follows:

(1) The development degree of the HS in Dalian and Kobe has shown a steady and fluctuating upward trend, respectively. The overall development level of Kobe has always been higher than that of Dalian, but the gap has gradually narrowed. In terms of natural environment and residential environment, Kobe has always been better than Dalian. In terms of population and cultural environment, Dalian has more advantages, and Kobe has not made significant progress. In terms of economic environment, Dalian is far ahead of Kobe before 2013; after that, it showed a phased decline, and Kobe caught it up in 2015.

(2) The coordination degree of urban HS of Dalian and Kobe has shown a good upward trend, and the overall coordination degree of HS development of Kobe is higher than that of Dalian. Kobe's HS coordination degree was in the stage of primary in 2005 , and then it steadily increased, which entered and stabilized at the stage of intermediate in 2014. Dalian's HS coordination degree was barely coordinated from 2005 to 2006, it has been maintained in the primary coordination stage from 2007 to 2017, but the degree of coordination decreased from 2012 to 2014, and began to slowly rise in 2015, until it developed to the stage of intermediate level in 2018.

(3) The sustainability of urban HS in Dalian and Kobe is in a fluctuating development state, and the average sustainable growth rate of HS in Dalian is higher than that in Kobe. The sustainability of Kobe's HS is relatively unstable, and the sustainable growth rate has been negative for nearly half of the years. The HS in Dalian was in a state of sustainable development from 2006 to 2011, but its sustainability weakened, and it was unsustainable from 2012 to 2014 and recovered to a state of sustainable development from 2015 to 2018.

(4) The sustainable development space of the HS in Dalian presents a pattern of "high in the south and low in the north." The spatial characteristics of the development level of each subsystem are different. The spatial differentiation characteristics of the natural environment and the residential environment are similar to the overall development spatial pattern. The humanity environment presents a spatial pattern of "high on both sides, low in the middle," and the economic environment development level presents a spatial pattern of "high in the east and low in the west." The main obstacles to the sustainable development of the HS in Dalian have changed from economic-natural to economic-natural-cultural-public services. Economic barriers have declined, and cultural and public services barriers have increased. In addition, there are also significantly differences in obstacle factors in each region. 
(5) The sustainable development of the urban HS in Kobe has a spatially high level of development in the southeast, radiating to the surroundings. The spatial characteristics of the development of each subsystem are different. The natural environment presents a "roof" pattern of differentiation in the middle $>$ west $>$ southeast. The areas with high levels of development of humanity environment, residential environment, and economic environment are concentrated in the southeast. The main obstacles to the sustainable development of the HS in Kobe have transitioned from economic-cultural-natural to economic-population and then to economic-natural-population. Economic barriers have declined and population structure barriers have increased. In addition, there are also differences in barrier factors in each region.

The limitations of this research are as follows. First, due to the limitation of data, the research unit of this paper is the urban area. For urban areas with a large area, the development level within the unit is also different. In the future, the division of research units can be improved to improve the accuracy of the research. Second, due to the limitation of long-term sequence analysis, the combination of network data and subjective survey data is not sufficient. In the future, dynamic and continuous accumulation of data can make the evaluation results more convincing and valuable.

5.2. Policy Implications. The research conclusions above reflect the different characteristics of the growth foundation and development path of the two cities. The urban development of Kobe is relatively mature, and that of Dalian is still in a rising period. Compared with Kobe, Japan's gradual, comprehensive, and detailed process of improving HS, the development model of HS in Dalian, China, is more extensive, and there are many remaining problems. In order to promote the coordinated and stable development of the HS in Dalian, it puts forward the following suggestions.

The construction of the ecological environment should be vigorously strengthened and green development should be comprehensively promoted. Beautiful natural landscapes, vast clear waters, and fresh air are the natural basic conditions for the sustainable construction of urban HS. Dalian should build a livable model city with stricter standards, improve the level of fine dust control, strengthen the city's accessibility of parks, expand the per capita public green area, promote the conservation and utilization of water resources, strengthen the control of marine pollution sources, implement garbage classification management, strengthen biodiversity protection, and comprehensively rectify phenomena that damage the HS, such as illegal occupation of roads, private construction, and random piles and at the same time build a green industry system vigorously, improve the level of green industry technology and equipment such as energy conservation, environmental protection, resource utilization, and so on, and exercise strong supervision over the adjustment of the energy structure to make the energy system cleaner, safer and more efficient.

The housing security system to achieve "living and livable" Should be improved. Residents' basic housing rights are guaranteed, which is conducive to social stability and harmony. Dalian's urban housing prices are relatively high, and urban residents are under greater pressure to buy houses. School districts and residential communities with better living conditions have relatively high housing prices. As a result, low- and middle-income and sandwich-class families are unbearable, and the relatively low-priced housing away from the city center has disadvantages such as inconvenient transportation and imperfect supporting facilities. Therefore, it is necessary to adhere to the peopleoriented and city-specific policies for housing security and real estate management, stabilize land prices and housing prices, and solve housing problems more accurately, indepth, and meticulously. At the same time, it should strengthen the governance and transformation of dilapidated houses, improve residential facilities, and upgrade community management capabilities, etc., to improve the happiness of residents.

Improve public service facilities and pay attention to disadvantaged groups. A sustainable urban HS should provide residents with high-accessibility, diversification, and level-based supporting service facilities. Dalian's public service facilities are concentrated in the southwest, leading to uneven development within the city and restricting the simultaneous improvement of the quality of life. It is necessary to build a high-quality public service system based on local conditions, such as improving the level of sanitation and health services, improving the built environment of communities, building an urban travel service system with public transportation as the main body, and launching national fitness exercises. In addition, it is necessary to fully respect and understand different social groups and meet differentiated needs to resist the lack of human care and insecurity in the construction of urban HS. For example, a safe outdoor activity space is needed for children. It is necessary to build high-standard community service centers for the elderly. For the disabled, it is necessary to improve supporting facilities and provide convenient and stress-free travel services.

Transform the economic development model and focus on driving urban economic growth with innovation and human capital. In order to resist economic downward pressure and promote the transformation and upgrading of urban industrial structure, we should no longer blindly pursue economic growth, but should emphasize the competitiveness, diversity, and stability of economic development. Firstly, the wisdom and branding of traditional competitive industries should be promoted, such as reshaping the "Dalian machine tool" brand, accelerating the construction of equipment manufacturing in Jinzhou District, building a strong marine economy, etc., while expanding strategic emerging industries, such as high-end equipment andnew energy vehicles; secondly, social innovation vitality should be promoted, which takes hightech parks as a demonstration, builds a modern industrial 
system with core competitiveness, increases efforts to build scientific and technological innovation platforms, such as Dalian Institute of Chemical Technology, Dalian University of Technology, and other scientific research institutes, and enhances technological transformation capabilities; thirdly, it must not only pay attention to cultivating talents, improve the quality of all kinds of education, and comprehensively improve the cultural literacy of residents, but also improve the talent introduction policy, select talents based on actual needs, and provide a source of power for talents.

\section{Data Availability}

The primary data used to support the findings of this study are available from the corresponding author upon request.

\section{Conflicts of Interest}

The authors declare no conflicts of interest.

\section{Acknowledgments}

This work was supported by the National Natural Science Foundation of China (Grant no. 41671158), Ministry of Education Humanities and Social Sciences Research Program (Grant no. 18YJCZH035), Liaoning Social Science Planning Fund Program (Grant no. L18CGL002), Liaoning Education Department Scientific Research Project (Grant no. J2020060), and Dalian Science and Technology Innovation Fund Project (Grant no. 2020JJ26GX039).

\section{References}

[1] A. K. Chowdhury, "Promoting the construction of global sustainable human settlements," Low Carbon World, vol. 14, pp. 13-14, 2013.

[2] J. M. Senoamadi, Intergovernmental Relations: Sustainable Human Settlements in the City of Tshwane Metropolitan Municipality in Gauteng Province, University of South Africa, Pretoria, South Africa, 2014.

[3] X. Zhao, H. Sun, B. Chen, X. Xia, and P. Li, "China's rural human settlements: qualitative evaluation, quantitative analysis and policy implications," Ecological Indicators, vol. 105, pp. 398-405, 2019.

[4] L. Tang, M. Ruth, Q. He, and S. Mirzaee, "Comprehensive evaluation of trends in human settlements quality changes and spatial differentiation characteristics of 35 Chinese major cities," Habitat International, vol. 70, pp. 81-90, 2017.

[5] J. J. Nieves, A. Sorichetta, C. Linard et al., "Annually modelling built-settlements between remotely-sensed observations using relative changes in subnational populations and lights at night," Computers, Environment and Urban Systems, vol. 80, Article ID 101444, 2019.

[6] W. Halik, A. Mamat, J. H. Dang, B. S. H. Deng, and T. Tiyip, "Suitability analysis of human settlement environment within the Tarim basin in Northwestern China," Quaternary International, vol. 311, pp. 175-180, 2013.

[7] P. K. R. Chowdhury, B. L. Bhaduri, and J. J. McKee, "Estimating urban areas: new insights from very high-resolution human settlement data," Remote Sensing Applications: Society and Environment, vol. 10, pp. 93-103, 2018.
[8] T. Chen, W. B. Wu, J. J. He et al., "Urban human settlements monitoring model and its application based on multi-source spatial data fusion," Acta Ecologica Sinica, vol. 39, no. 4, pp. 1300-1308, 2019.

[9] B. Chen, Y. M. Song, B. Huang, and B. Xu, "A novel method to extract urban human settlements by integrating remote sensing and mobile phone locations," Science of Remote Sensing, vol. 1, Article ID 100003, 2020.

[10] T. V. T. Nguyen, H. Y. Han, and N. Sahito, "Role of urban public space and the surrounding environment in promoting sustainable development from the lens of social media," Sustainability, vol. 11, no. 21, pp. 1-15, 2019.

[11] C. Li, "Comprehensive evaluation of human settlements in 36 central cities of China," Journal of Arid Land Resources and Environment, vol. 31, no. 5, pp. 1-6, 2017.

[12] Y. Q. Gu, J. Yang, X. L. Feng, C. Li, and X. M. Li, "Spatial differentiation of human settlement environment suitability in Chinese typical tourist cities," Scientia Geographica Sinica, vol. 35, no. 4, pp. 410-418, 2015.

[13] J. A. Parry, S. A. Ganaie, and M. Sultan Bhat, "GIS based land suitability analysis using AHP model for urban services planning in Srinagar and Jammu urban centers of J\&K, India," Journal of Urban Management, vol. 7, no. 2, pp. 46-56, 2018.

[14] J. V. Meijering, H. Tobi, and K. Kern, "Defining and measuring urban sustainability in Europe: a Delphi study on identifying its most relevant components," Ecological Indicators, vol. 90, pp. 38-46, 2018.

[15] S. Krishnan and M. Firoz, "Regional urban environmental quality assessment and spatial analysis," Journal of Urban Management, vol. 9, no. 2, pp. 191-204, 2020.

[16] M. A. Mohit and S. A. Iyanda, "Liveability and low-income housing in Nigeria," Procedia-Social and Behavioral Sciences, vol. 222, pp. 863-871, 2016.

[17] A. Komeily and R. S. Srinivasan, "A need for balanced approach to neighborhood sustainability assessments: a critical review and analysis," Sustainable Cities and Society, vol. 18, pp. 32-43, 2015.

[18] W. Musakwa, R. M. Tshesane, and M. Kangethe, "The strategically located land index support system for human settlements land reform in South Africa," Cities, vol. 60, pp. 91-101, 2017.

[19] F. Sabo, C. Corbane, A. J. Florczyk, S. Ferri, M. Pesaresi, and T. Kemper, "Comparison of built-up area maps produced within the global human settlement framework," Transactions in GIS, vol. 22, no. 6, pp. 1406-1436, 2018.

[20] X. M. Li and P. Y. Jin, "Characteristics and spatial-temporal differences of urban human settlement environment in China," Scientia Geographica Sinica, vol. 32, no. 5, pp. 521-529, 2012.

[21] Q. Q. Yang, J. Chen, B. H. Li, and Y. Y. Zhu, "Evolution and driving force detection of urban human settlement environment at urban agglomeration in the middle reaches of the Yangtze river," Scientia Geographica Sinica, vol. 38, no. 2, pp. 195-205, 2018.

[22] X. X. Jing, S. L. Ye, X. Y. Wu, Y. Wang, and Y. Cheng, “A quality evaluation of human settlements in island cities: a comparison between Xiamen and Pingtan," Acta Ecologica Sinica, vol. 36, no. 12, pp. 3678-3686, 2016.

[23] J. Yang, X. M. li, Y. H. Li, C. Z. Sun, and F. X. Wang, "Assessment on spatial differences of human settlement environment in communities based on DPSIRM model: the case study of Dalian," Geographical Research, vol. 31, no. 1, pp. 135-143, 2012.

[24] A. G. Aguilar, "Peri-urbanization, illegal settlements and environmental impact in Mexico city," Cities, vol. 25, no. 3, pp. 133-145, 2008. 
[25] M. Zarei and M. Zakeri, "Strategic planning of human settlement development of Qeshm island by using SWOT model," World Review of Science, Technology and Sustainable Development, vol. 13, no. 4, pp. 382-396, 2017.

[26] W. M. Zhao and Y. Wang, "Theoretical construction of mountain human settlements info-spectrum and its academic significance," City Planning Review, vol. 38, no. 4, pp. 9-16, 2014.

[27] J. Montoya, I. Cartes, and A. Zumelzu, "Indicators for evaluating sustainability in Bogota's informal settlements: definition and validation," Sustainable Cities and Society, vol. 53, Article ID 101896, 2020.

[28] N. K. Asare-Donkor, T. A. Boadu, and A. A. Adimado, "Evaluation of groundwater and surface water quality and human risk assessment for trace metals in human settlements around the Bosomtwe Crater lake in Ghana," SpringerPlus, vol. 5, p. 1812, 2016.

[29] S. Lhoest, D. Fonteyn, K. Daïnou et al., "Conservation value of tropical forests: distance to human settlements matters more than management in central Africa," Biological Conservation, vol. 241, Article ID 108351, 2020.

[30] R. Rante, E. Fouache, and D. Mirzaakhmedov, "Dynamics of human settlements ensuing from river transformation and changes in commercial behaviour: the birth of the "northeastern silk road"," Journal of Archaeological Science: Reports, vol. 9, pp. 437-447, 2016.

[31] A. J. Njoh, "Modernist urban planning as a tool of acculturation: implications for sustainable human settlement development in Cameroon," City, Culture and Society, vol. 4, no. 2, pp. 111-120, 2013.

[32] W. R. Dickinson, "Beach ridges as favored locales for human settlement on Pacific islands," Geoarchaeology, vol. 29, no. 3, pp. 249-267, 2014.

[33] H. Badland, S. Mavoa, C. Boulangé et al., "Identifying, creating, and testing urban planning measures for transport walking: findings from the Australian national liveability study," Journal of Transport \& Health, vol. 5, pp. 151-162, 2017.

[34] C. C. Türkyılmaz, "Interrelated values of cultural landscapes of human settlements: case of Istanbul," Procedia-Social and Behavioral Sciences, vol. 222, pp. 502-509, 2016.

[35] Q. Mao, "Theory and practice of the science of human settlements in China," Urban Planning International, vol. 34, no. 4, pp. 54-63, 2019.

[36] H. Li, X. M. Li, S. Z. Tian, S. B. Li, and P. F. Zhao, "Temporal and spatial variation characteristics and mechanism of urban human settlements: case study of Liaoning province," Geographical Research, vol. 36, no. 7, pp. 1323-1338, 2017.

[37] Y. Wang, C. Jin, M. Lu, and Y. Lu, "Assessing the suitability of regional human settlements environment from a different preferences perspective: a case study of Zhejiang province, China," Habitat International, vol. 70, pp. 1-12, 2017.

[38] Y. G. Cong, B. Xia, and L. H. Wei, "Research of polarization and human settlements satisfactory of communities in Guangzhou," Human Geography, vol. 28, no. 4, pp. 53-57, 2013.

[39] S. Schetke, D. Haase, and T. Kötter, "Towards sustainable settlement growth: a new multi-criteria assessment for implementing environmental targets into strategic urban planning," Environmental Impact Assessment Review, vol. 32, no. 1, pp. 195-210, 2012.

[40] X. M. Li, Y. J. Guo, S. Z. Tian, Z. Z. Bai, and H. Liu, "The spatio-temporal pattern evolution and driving force of the coupling coordination degree of urban human settlements system in Liaoning province," Scientia Geographica Sinica, vol. 39, no. 8, pp. 1208-1218, 2019.

[41] F. J. Aceituno and N. Loaiza, "The role of plants in the early human settlement of northwest south America," Quaternary International, vol. 363, pp. 20-27, 2015.

[42] G. A. Martínez, D. L. Mazzanti, C. Quintana et al., "Geoarchaeological and paleoenvironmental context of the human settlement in the eastern Tandilia range, Argentina," Quaternary International, vol. 299, pp. 23-37, 2013.

[43] C.-w. Xiao, Z.-m. Feng, P. Li, Z. You, and J.-k. Teng, "Evaluating the suitability of different terrains for sustaining human settlements according to the local elevation range in China using the ASTER GDEM," Journal of Mountain Science, vol. 15, no. 12, pp. 2741-2751, 2018.

[44] S. Rezaian, "Environmental, health, and safety risks of the power lines nearby the human settlements," Human and Ecological Risk Assessment: An International Journal, vol. 22, no. 8, pp. 1696-1707, 2016.

[45] H. Shekhar, A. J. Schmidt, and H.-W. Wehling, "Exploring wellbeing in human settlements-a spatial planning perspective," Habitat International, vol. 87, pp. 66-74, 2019.

[46] Y. Y. Song, D. Q. Xue, and L. H. Dai, "Spatial-temporal pattern and evolution mechanism of coordinated development of human settlement environment and economy in energy accumulation and vulnerable ecology regions: a case of contiguous areas among Shanxi-Shaanxi-Inner Mongolia," Arid Land Geography, vol. 40, no. 6, pp. 1328-1337, 2017.

[47] N. Chabbi-Chemrouk and N. Driouèche, "Urban solidarity, a key issue to sustainable human settlements," Procedia Engineering, vol. 21, pp. 707-710, 2011.

[48] J. Y. Yang, J. Yang, X. Y. Luo, and C. H. Huang, "Impacts by expansion of human settlements on nature reserves in China," Journal of Environmental Management, vol. 248, Article ID 109233, 2019.

[49] A. B. Reinmann, L. R. Hutyra, A. Trlica, and P. Olofsson, "Assessing the global warming potential of human settlement expansion in a mesic temperate landscape from 2005 to 2050," Science of The Total Environment, vol. 545-546, pp. 512-524, 2016.

[50] A. E. Larsen, A. J. MacDonald, and A. J. Plantinga, "Lyme disease risk influences human settlement in the wildlandurban interface: evidence from a longitudinal analysis of counties in the northeastern United States," The American Journal of Tropical Medicine and Hygiene, vol. 91, no. 4, pp. 747-755, 2014.

[51] L. Y. Wu, Introduction to Sciences of Human Settlements, China Architecture \& Building Press, Beijing, China, 2001.

[52] Y. Asami, Residential Environment: Evaluation Method and Theory, Tsinghua University Press, Beijing, China, 2006.

[53] D. G. Tout, "The discomfort index, mortality and the London summers of 1976 and 1978," International Journal of Biometeorology, vol. 24, no. 4, pp. 323-328, 1980.

[54] W. H. Terjung, "Physiologic climates of the conterminous United States: a bioclimatic classification based on man," Annals of the Association of American Geographers, vol. 56, no. 1, pp. 141-179, 1966.

[55] C. R. D. Freitas, "Human climates of northern China," Atmospheric Environment, vol. 13, no. 1, pp. 71-77, 1979.

[56] T. B. Mckee, N. J. Doesken, and J. Kleist, "The relationship of drought frequency and duration to time scales," in Proceedings of the 8th Conference on Applied Climatology, Anaheim, CA, USA, January 1993.

[57] H. Mayer, L. Makra, F. Kalberlah, D. Ahrens, and U. Reuter, "Air stress and air quality indices," Meteorologische Zeitschrift, vol. 13, no. 5, pp. 395-403, 2004. 
[58] S. Li, H. Wei, X. L. Ni, Y. W. Gu, and C. X. Li, "Evaluation of urban human settlement quality in Ningxia based on AHP and the entropy method," Chinese Journal of Applied Ecology, vol. 25, no. 9, pp. 2700-2708, 2014.

[59] C. Wang, H. Y. Li, Y. Z. He, X. S. Ma, and M. M. Zhou, "Sustainable development ability and its spatiotemporal differentiations of rural human settlements in Chongqing municipality from 1997 to 2015," Progress in Geography, vol. 38, no. 4, pp. 556-566, 2019. 